\title{
Uber den Röhrenbau und die Nahrungsaufnahme einiger Spioniden (Polychaeta sedentaria) der deutschen Küsten
}

\author{
Von Christine Hempel \\ Aus dem Zoologischen Institut der Universität Kiel \\ und der Biologischen Anstalt Helgoland in List auf Sylt ${ }^{1}$ )
}

(Mit 16 Abbildungen)

Inhaltsübersicht

I. Untersuchungsgebiet und Methodik S. 101. - II. Zur Morphologie der Arten S. 101-103. - III. Bau der Polydora-Röhre S. 103-110. - IV. Das Bohren von Polydora ciliata S. 110-122. - V. Die Pygospio-Wohnröhre S. 122-124. - VI. Brutpflege und Festsetzen der Larven S. 124-127. - VII. Die Nahrungsaufnahme der Spioniden S. 127-130. VIII. Zur geologischen Auswertbarkeit der Ergebnisse S. 131-132. - IX. Zusammenfassung S. 132-134. - X. Literaturverzeichnis S. 134-135.

Das Eindringen der sedentären Polychäten in den Boden ist ein interessantes biologisches Problem. Ihm kommt auch für die Paläontologie große Bedeutung zu, da die Wurmröhren mit zu den ältesten Lebensspuren zählen.

Über den Röhrenbau der an unseren Küsten lebenden Spioniden ist bisher nicht viel bekannt. Die strukturell nur wenig voneinander unterschiedenen Polydora-Arten und Pygospio elegans besiedeln sehr verschiedene Biotope. Es war daher von Interesse zu untersuchen, wie das Eingraben ins Sediment und der Röhrenbau den Bedingungen der Sand- und Weichböden angepaßt ist. Außerdem war die Frage, ob bei der Herstellung der Bohrlöcher mechanische oder chemische Kräfte wirken, für Polydora wie für viele andere in Hartböden siedelnde Tierarten noch ungelöst. Hierzu wurde besonders das Verhalten von Polydora ciliata studiert. Ein weiteres Problem war, welche Schutzeinrichtungen den hier betrachteten Polychäten das Leben in der Brandungszone ermöglichen und welche Beziehungen Ernährung und Brutpflege zu Biotop und Wohnweise haben.

Folgende Arten wurden untersucht:

Polydora quadrilobata JACOBI, Polydora ligni WEBSTER, Polydora redeki HORST, Polydora ciliata JOHNSTON und Pygospio elegans CLAPAREDE.

1) Herrn Prof. Dr. A. Remane, meinem verehrten Lehrer, möchte ich für die Anregung zu dieser Arbeit, sein Interesse «nd alle Förderung an dieser Stelle Dank sagen. 


\section{Untersuchungsgebiet und Methodik}

Beobachtungen und Material für die vorliegende Arbeit wurden vom Frühjahr 1954 bis zum Winter 1955 gesanmelt ${ }^{2}$ ). Im Eulitoral der Kieler Bucht wurden Strandgebiete zwischen Flensburg und Fehmarn untersucht. An der Nordsee sind in je fünfwöchigem Aufenthalt Untersuchungen in den Wattgebieten von Mellum in der Jade (März-April 1954) und im Königshafen von List/Sylt (Juni-September 1955) durchgeführt. Einzelne Proben wurden an fünf weiteren Stationen des Nordseelitorals genommen. Neun jahreszeitlich verschiedene Kontrollserien stammen aus dem Nordostseekanal und eine aus der Schlei.

An der Ostseeküste wurden außerdem an vier verschiedenen Stellen von fünf zu fünf Metern Wassertiefe Profile gelegt. Die Bodengreiferfänge ergaben einige Fundorte in verschiedenen Sedimenten des Sublitorial. Die von Polydora ciliata angebohrten Kalksteine und Molluskenschalen wurden teilweise bei den Exkursionen an der Nord- und Ostseeküste im Angespül und Geschiebe gesammelt. Dieses Material stammt hauptsächlich aus Dredschfängen auf den Austernbänken vor List, den Lister und Mellumer Mytilus-Bänken und dem Pfahlbewuchs in der Kieler Bucht.

An der französischen Mittelmeerküste und auf Mallorca konnte ich im Herbst 1954 kursorische Beobachtungen zur Okologie und Biologie einiger Arten sammeln.

Die Art der Probenahme war für die einzelnen Biotope sehr verschieden. Bei den Proben aus dem Sublitoral und bei den aus dem Nord-Ostsee-Kanal und der Schlei handelt es sich um Dredsch- und Bodengreiferfänge, die von den Forschungsfahrzeugen "Südfall" und "Ellenbogen" aus durchgeführt wurden. Von diesen Fängen wusch ich die oberflächlichen Schichten sorgfältig in der von $\mathrm{Ax}$ (1951) beschriebenen Weise aus. Der Auswaschrüdkstand wurde in Gläsern. deren Boden mit gründlich ausgewaschenem Substrat des betreffenden Biotopes gefüllt war, mit frischem Wasser gehältert. Die Proben wurden zunächst kühl gestellt und im Labor in durchlüftete Aquarien auf reinen Seesand gebracht.

Am Strand und in den Watten wurden aus Spionidensiedlungen kleinere Substratproben ausgewaschen und der Rückstand in der gleichen Weise gehältert oder es wurden „Kleinsiedlungen" möglichst unversehrt mit einer kleinen Schaufel ausgestochen und sofort in Beobachtungsschalen gesetzt. Die Beobachtungen von Röhrenbau und Lebensweise konnten am natürlichen Standort und zum Teil im Labor unter dem Binokular durchgeführt werden. Die Darstellung des Röhrenbaus basiert auf Beobachtungen an erwachsenen Tieren. Das Verhalten der jungen, benthonischen Stadien wird in einem gesonderten Abschnitt behandelt. Diese Untersuchungen werden fortgesetzt. Eine Beschreibung der Methode im einzelnen folgt in den entsprechenden Kapiteln $\left.{ }^{3}\right)$.

\section{Zur Morphologie der Arten}

Die Morphologie der im Dienste des Röhrenbaus stehenden Körperabschnitte kann, infolge nur geringer Unterschiede, für alle Polydora-Arten gemeinsam behandelt werden. Demgegenüber zeigt $P$ ygospio einige stärkere $\mathrm{Ab}-$ weichungen, die mit der teilweise anderen Lebensweise gut übereinstimmen. Genaue anatomisch-histologische Untersuchungen an Polydora ciliata und $P$. quadrilobata führte ЈАСоВі (1883) durch.

2) Eine ausführliche Darstellung der Verbreitung und Okologie der hier untersuchten Arten erscheint in Kieler Meeresforschung 13 (1957).

3) Herrn Prof. Dr. Wüst danke ich für die Erlaubnis, an Materialsammelfahrten des Forschungsschiffes "Südfall" teilzunehmen. Außerdem möchte ich Herrn Dr. Aurich, Biologische Anstalt Helgoland, List auf Sylt, und Herrn Prof. Dr. Perrit, Laboratoire Arago, Banyuls-sur-Mer, vielmals danken, die mit bei der Materialbeschaffung behilflich waren, indem sie mir freundlich Arbeitsmöglichkeit in ihren Instituten gaben, und Herrn Prof. Dr. Drost, Vogelwarte Helgoland, der mir einen fünfwöchigen Aufenthalt auf der Vogelinsel Mellum ermöglichte. Herrn Prof. Dr. Bargmann, Anatomisches Institut der Universität Kiel (Abb. 12, 14), und Herrn Dr. Ziegelmeier, Biologische Anstalt Helgoland (Abb. 9, 10, 16), danke ich für die Unterstützung bei der Herstellung der fotografischen Aufnahmen. 
Der Kopflappen (Prostomium) trägt ein Paar zylindrischer Tentakeln, die am hinteren Ende des Kopfabschnittes entspringen und bei Polydora etwa die Länge von 20-25 Körpersegmenten erreichen. Der Hohlraum des Tentakels (Abb. 1) ist mit Bindegewebe erfüllt, das von feinen Muskelfasern durchzogen wird. An den Wänden setzen kräftige Ring- und Längsmuskeln an, die eine Bewegung des Tentakels nach allen Seiten ermöglichen. Die ventrale Tentakelseite ist bewimpert und bildet eine mehr oder weniger tiefe Rinne. $\mathrm{Zu}$ dieser Hauptrinne führen von den Rändern her kleine Vertiefungen - Wimperbänder - die in regelmäßigem Abstand angeordnet sind. Die Cilien der Hauptrinne schlagen mundwärts, die der Wimperbänder in Richtung der Hauptrinne. Rechts und links von der Ventralseite des Tentakels liegt ein Saum von Papillen, von der jede mit einer Tastborste versehen ist. Diese stehen mit dem Nervensystem in Verbindung. Am vorderen Ende des Tentakels sind sie dichter angeordnet, die Wimperrinne ist dort schmäler. Die Tastborsten können sich zur Mitte neigen.

Die Hauptaufgabe der Tentakel ist der Transport von Nahrung und Baumaterial. Die Polydora-Arten fangen kleine Teilchen aus dem freien Wasser, Pygospio dagegen sammelt mit verhältnismäßig dicken Tentakeln, die langsamer bewegt werden, an der Bodenoberfläche. Kleine Nahrungsteilchen und Bausteine können durch gerichteten Cilienschlag "wie auf einem Förderband" zur Mundöffnung geleitet werden. Bei größeren Fremdkörpern hilft Druck von den Seiten der Rinne mit beim Transport. Sehr große Sandkörner und Nahrungspartikel werden, wenn sie an der Tentakelspitze festgeheftet sind, durch Kontraktion oder Einrollung des Tentakels zur Mundöffnung gebracht. Diese Arbeitsweise ist sehr ähnlich derjenigen, die Dales (1955) für den Tentakel einer Terrebellide beschreibt.

Längs der Ventralseite des Prostomiums liegt bei den Polydora-Arten als Mundöffnung (Abb. 2) ein breiter, bewimperter Spalt. Die Trichterwand, die durch Verlängerung des Pharynx das "Munddach" bildet; ist nach innen zu eingeschlagen. Diese nach oben hin breiter werdende Einstülpung überragt den Rand des Prostomium, sie wird als zungenförmiges Organ bezeichnet. Auch dieses ist bewimpert. Rechts und links von der Mundöffnung verlaufen zwei bewimperte Wülste. Der an der Innenseite bewimperte Pharynx reicht bis zum 2. Segment, sein Epithel ist drüsenreich. Am hinteren Ende bildet er eine Falte, welche durch kräftige Muskelfasern, die an einer Ringmuskelschicht ansetzen, gestredkt werden kann. Dadurch ist die Mundöffnung bis über den ventralen Spalt vorschiebbar. - Bei Pygospio elegans ist die Mundöffnung anders gestaltet (Abb. 3). Sie wird von einer ventral gelappten, trichterförmigen Erweiterung des Pharynx gebildet.

JACOBI fand in den Tentakeln eine Arterie und eine Vene, aber kein verzweigtes Kapillarsystem, wie es bei vielen anderen Polychätenarten vorkommt. Beim Ausstrecken der Tentakeln schießt das Blut in die Gefäßstämme, im kontrahierten Zustand sind sie blutleer

Die Kiemen beginnen bei Polydora redeki am 2. Segment, bei den anderen Polydora-Arten nach dem fünften. Bei Pygospio liegen sie bei den Weibchen zwischen dem elften und zwanzigsten Segment (7-9 Paar), die Männchen haben nach dem elften Segment häufig 20-28 Paar und außerdem ein Paar große Kiemen am 2. Segment. Die Kiemenblättchen von Pygospio sind viel kleiner als die der Polydoren. Auf der dem Körper zugewandten Seite tragen sie eine Wimperreihe, deren Gilien nach beiden Seiten schlagen 

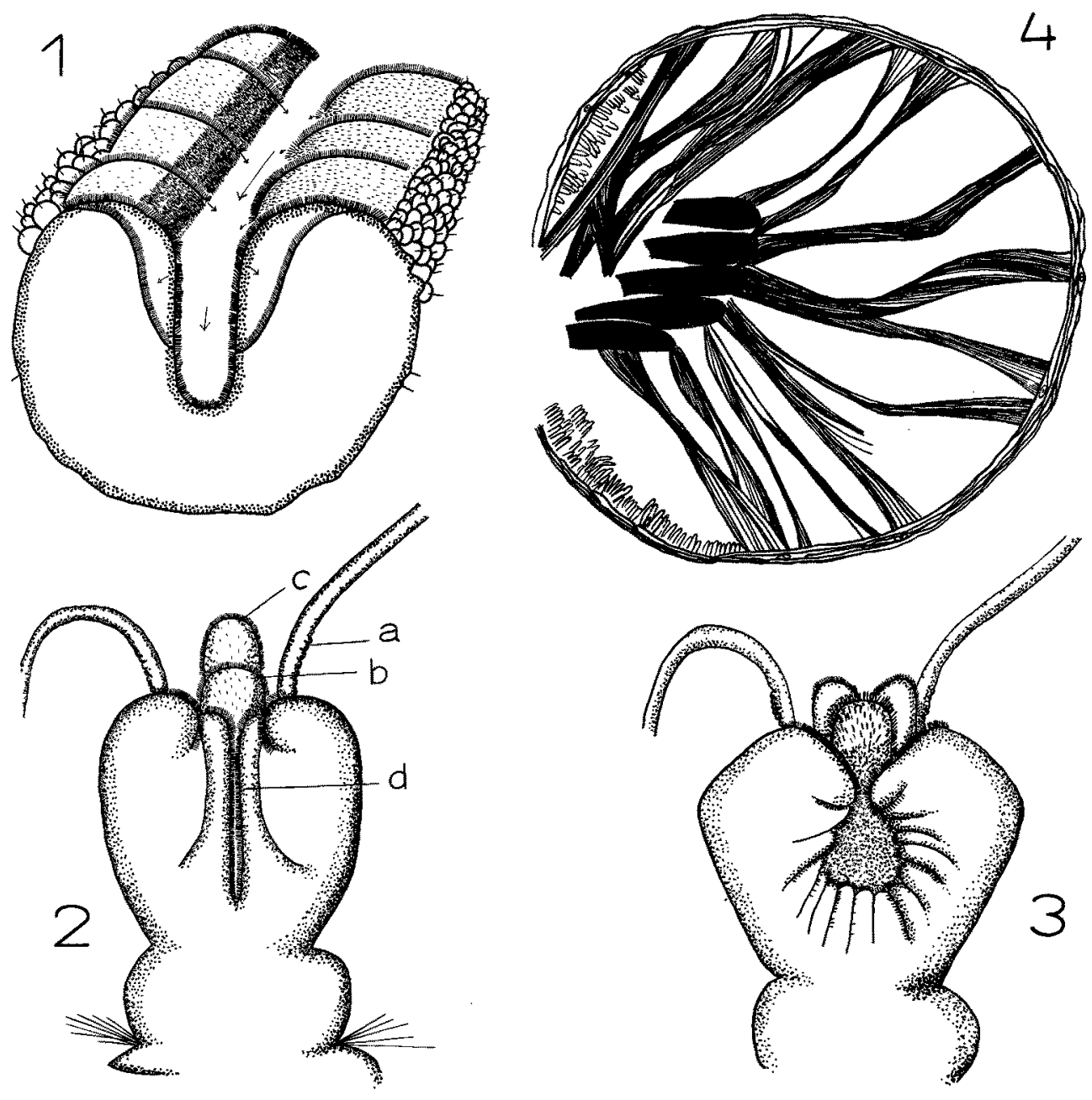

Abb. 1. Mittlere Region eines Polydora-Tentakels. Der Tentakel ist im Querschnitt nierenförmig. Zur Hauptrinne führen von den Seiten her Wimperbänder. Am Rande stehen mit Stiften versehene Papillen. Baumaterial und Nahrung werden durch Wimperschlag in Pfeilrichtung befördert. Die Rinne kann erweitert werden (schematisch)

Abb. 2. Prostomium von Polydora ciliata: 1. Tentakel, 2. Zungenförmiges Organ, 3. mediandorsaler Wulst, 4. Bewimperter Mundschlitz (Ventralansicht)

Abb. 3. Prostomium von Pygospio elegans (Ventralansicht)

Abb. 4. Muskulatur in der Borstentasche des 5. Segmentes von Polydora ciliata. An der Ringmuskulatur setzen strahlenförmig starke Muskelbänder an, durch welche die Borsten bewegt werden (schematisch) 
können. Im Gegensatz zu den Polydoren dienen bei Pygospio vorwiegend die Tentakel als Atemorgane.

Die Bèwaffnung mit mehreren großen messerartigen Borsten am fünften Segment ist Gattungsmerkmal für Polydor $a^{4}$ ). In Anzahl und Form unterscheiden sie sich bei den einzelnen Arten. Das fünfte Segment ist mit einer besonders starken Muskulatur versehen. Zu der Ringmuskulatur, die das Segment umschließt, verlaufen strahlenförmig Muskelfasern, welche an der Borstentasche ansetzen (Abb, 4). Dadurch sind die Borstenbündel in mehreren Ebenen gut beweglich. Die einzelnen Borsten können jedoch nur wenig gegeneinander verschoben werden. - Abgesehen von diesen Messerborsten tragen die Parapodien des fünften, wie der folgenden Segmente mehrere feine Haar-borsten. Bei Pygospio kommen keine Messerborsten vor.

Für die Gattung Polydora sind zwei Arten von zusammengesetzten Drüsen charakteristisch (Claparède 1870, JACOBI). Am sechsten und den folgenden Segmenten finden sich die paarigen "poches glanduleuses" (CLAPARĖDE), welche im siebenten und achten Segment am stärksten entwickelt sind. Nach JАСові sind sie birnenförmig und bestehen außerdem aus mehreren schlauchförmigen Drüsenzellen, die jede einzeln am unteren Ast des Parapodiums ausmünden.

Nach Hannerz (1956) treten diese "poches glanduleuses" schon bei den Larven auf. Im metamorphose-reifen Stadium liegen sie in den Segmenten 7 , 8 und 9 und bestehen dort jede aus vier oder fünf Zellen. Im gleichen Stadium (17-20 Segmente) fand er im 5. Segment 1 Paar Drüsen, die den „poches glanduleuses" vergleichbar sind; sie haben die Länge der Bohrborsten und stehen mit der Borstentasche in Verbindung. Die Ausmündung liegt unter den Borstenspitzen; bei der Metamorphose werden sie geschlossen. Das schleimige Sekret dieser Drüsen reagiert sauer. - Für Polydora ciliata und quadrilobata beschreibt JACOBI in den Segmenten 7-9 noch andere paarige Drüsenkomplexe (JACoBrsche Drüsen), die besonders bei Polydora quadrilobata sehr groß sein können. Sie münden jede einzeln ventral. (JACOBI verglich diese Drüsen mit denen, die von Claparède für Fabricia armandi Clap. und von Steen für Terrebellides strömii Sars beschrieben wurden.) Sie sezernieren einen Schleim, der beim Bau der Röhren als Kitt dient. Auch Pygospio elegans hat, besonders in der mittleren Körperregion, große Schleim produzierende Drüsen. - Der Hautmuskelschlauch ist bei den Polydora-Arten und Pygospio kräftig entwickelt. Dadurch können sie sich auch außerhalb der Röhre schnell schlängelnd oder kriechend bewegen.

\section{Bau der Polydora-Röhre}

\section{Polydora quadrilobata}

Polydora quadrilobata siedelt in Sand- und Weichböden des Eu- und Sublitorals. Die Art ist nicht an bestimmte Korngrößenzusammensetzungen des Sedimentes gebunden. Besonders günstig erscheinen die Lebensbedingungen am Rande von flachen Prielen oder in einem Lanice-Rasen nahe der NW-Linie. In beiden Gebieten ist das Angebot an Bodentrübe sehr groß. Das grobe Sediment in der Lanice-Siedlung bietet außerdem den Larven günstige An-

4) Zwei andere, in Kalk bohrende Polydora-Arten, die am Mittelmeer häufig vorkommen, Polydora armata Clap. und Polydora hoplura Clap. tragen außerdem an den letzten Segmenten einige Messerborsten. 
satzmöglichkeiten. Alle Fundorte liegen in Wattabschnitten, die nur kurze Zeit trocken fallen oder doch ständig von einem Wasserfilm bedeckt sind.

Die Bauweise der U-förmigen Röhren ist am deutlichsten bei Polydora quadrilobata zu erkennen, sie soll daher hier ausführlicher betrachtet werden. Als Baumaterial finden wir erhärteten Schleim, der von Drüsen des Tieres ausgeschieden wurde und eine Hülle bildet. In diese sind kleine Fremdkörper, Sandkörner, Detritus, Muschelbruchstücke und Pflanzenteilchen eingebaut.

An den im Freiland erstellten Röhren von $P$. quadrilobata können deut lich drei Abschnitte unterschieden werden.

1. Über die Bodenoberfläche ragen zwei Schornsteine. Sie bestehen aus zusammengekittetem Detritus und sind innen mit einer Schleimtapete ausgekleidet.

2. An der Bodenoberfläche wird neben feinem auch gröberes Baumaterial verwendet und feste Schleimbänder verankern das Röhrensystem an einigen großen Sandkörnern.

3. Im Bodeninneren besteht die Röhrenwand aus erhärtetem Schleim, in dem unterschiedlich großes Baumaterial ganz unregelmäßig verteilt ist. Besonders in der Biegung des $U$ ist das System sehr instabil. (Länge der im Sediment verlaufenden Röhrenschenkel $2-7 \mathrm{~cm}$, ihr Abstand 1-3 cm.)

Unter fünf Röhren ist durchschnittlich eine abweichend gestaltet, und zwar entweder W- oder UU-förmig, wobei die einzelnen Schenkel abwechselnd bewohnt werden; andere Röhren verlaufen im flachen Bogen unter der Bodenoberfläche.

Um die Tiere beim Bauen beobachten zu können, wurden Aquarienbeobachtungen durchgeführt.

Dazu wurden im Freiland ausgegrabene und in der Hand sehr vorsichtig vom umgebenden Sediment freigewaschene Röhren in gut durchlüfteten Aquarien auf reinen Seesand gelegt. Nachdem sich die Tiere eine zeitlang adaptiert hatten, veranlaßte ich einige durch feine Nadelstiche zum Verlassen ihrer Röhren und beobachtete den Neubau der Röhren dann in Schalen unter dem Binokular. Um den Bau im Inneren des Sedimentes verfolgen zu können, wurden die Polydoren in schmale Küvetten mit Sediment gesetzt (vgl. Ziegelmerer 1952), das dem des natürlichen Standortes entsprach.

Der Wurm beginnt sofort, nachdem er auf das Substrat gelegt ist, unter peristaltischen Bewegungen mit Schleimabsonderung. Das Tier kriecht vorwärts und rückwärts und legt sich auf die Seite. Der vordere Abschnitt des Körpers wird dabei am stärksten bewegt. Nachdem auf diese Weise eine provisorische Röhre entstanden ist, wie sie ZIEGELMEIER auch für Lanice beschreibt, werden die Tentakeln nach hinten gelegt und der Wurm schiebt sich mit dem Vorderende zwischen die Sandkörner, welches dabei hin- und herbewegt wird oder spiralige Bewegungen ausführt. So wird das Substrat zur Seite gedrängt (Abb. 5a). Besonders die Borsten des fünften Segmentes unterstützen das Prostomium durch schnelle Bewegungen von vorn nach hinten bei der Grabtätigkeit. Nach je drei oder vier Minuten wird eine Ruhepause eingelegt, wobei der vordere Körperabschnitt im Boden verbleibt. Erst wenn das Tier mit allen kiementragenden Segmenten eingegraben ist, dreht es sich in dem geschaffenen Hohlraum um, so daß jetzt das Hinterende im Sande steckt. Durch starke Schleimproduktion wird ein Nachsickern des Sedimentes verhindert.

Das Tier beginnt nun mit dem Schornsteinbau. Dieser Bauabschnitt wurde 
nicht nur im Aquarium, sondern auch im Freiland beobachtet (Abb. 5b). Die Tentakel gleiten in kurzen schnellen Bewegungen über die Bodenoberfläche oder schieben sich ein wenig zwischen die großen Sandkörner. Das herbeigeflimmerte Material gleitet dann in der Tentakelrinne zum Prostomium. Es wird von der taschenförmigen Mundöffnung aufgenommen und in die Tiefe der Röhre hinuntergezogen.

Entweder wird nach einer Weile das Material wieder aus der Röhre herausgeworfen oder die Mundöffnung legt sich über den Röhrenrand, und durch das Vorstülpen des Pharynx werden die in der Tasche gehaltenen Sandkörnchen - inzwischen mit Schleim vermischt - herausgedrückt und gleich Bausteinchen mauerartig aneinandergefügt. Wenn man das Sediment, welches die Röhre umgibt, ein wenig aufwirbelt, so daß feine Partikel im Wasser schweben, schwenkt der Wurm seine Tentakel durch das Wasser und sammelt damit alle Teilchen ein, die für ihn erreichbar sind. Häufig wird dann das $\mathrm{Ma}$ terial zunächst in die Röhre eingebracht, neues Material gefischt, und erst nach einer Weile wird der in der Röhre gesammelte Vorrat eingebaut. (Die Nahrung wird auf die gleiche Weise wie das Baumaterial mit den Tentakeln herangeholt.) Dieser erste Schornstein wird nur ein Stück weit erstellt. Die Bautätigkeit dauert bei reichlichem Angebot von Detritus ungefähr 21/2 Stunden. Der Gang im Inneren des Sedimentes wird noch etwas erweitert, danach ein zweiter Ausgang geschaffen und auch auf diesen ein Schornstein aufgesetzt (Abb. 5c). Erst dann wird der Gang im Inneren vervollständigt, zu dessen Ausbau zum Teil auch mit den Tentakeln eingebrachtes Sediment von der Bodenoberfläche verwendet wird. Dieses war nachzuweisen, indem den Tieren an der Bodenoberfläche feingemahlene Ziegelsteinsplitter oder mit Sudanrot gefärbter Sand geboten wurden, die später auch in der Röhrenwand im Bodeninneren $z u$ finden waren.

Neben grobsandigem Sediment einer Lanice-Siedlung, in dem P. quadrilobata im Königshafen-Watt mit der größten Siedlungsdichte auftrat, wurden den Tieren im Aquarium in anderen Versuchen sehr feine Korngrößen vorgelegt. Das Eingraben dauerte in diesem Falle wesentlich länger. Im Gegensatz zum vorhergehenden Versuch, bei dem sich die Tiere fast senkrecht in den Boden hineingearbeitet hatten, blieben sie, handelte es sich um feinen Sand, dicht unter der Oberfläche.

Im Aquariumsversuch fehlt die Verankerung des Schornsteins an großen Sandkörnern der Bodenoberfläche. In dem Schornstein, der am natürlichen Standort selbst in einer grobsandigen Lanice-Siedlung nur aus Detritusmaterial besteht, wurden im Aquarium auch Sandkörner mit eingebaut. Sonst sieht die im Aquarium wie die im Freiland gebaute Röhre aus. Daher dürfte der normale Arbeitsgang dem im Aquarium beobachteten entsprechen.

Bei Mangel an feinen Sinkstoffen werden einzelne Sandkörner umgedreht und „abgeweidet". Gewöhnlich wird der Detritus aus dem Wasser gefischt oder an der Bodenoberfläche gesammelt. Den Arbeitsgang konnte man bei einem Röhrensystem, das frei in einen Arenicola-Trichter hineinragte, gut beobachten.

Während der Niedrigwasserzeit zieht sich der Wurm ganz in seine Röhre zurück, kommt aber sofort mit seinen Tentakeln heraus, wenn das Wasser einer neuen Flut die Röhre überspült. Dieses enthält immer besonders viel Bodentrübe, Detritus, und es beginnt sofort eine lebhafte Tentakeltätigkeit. Am natürlichen Standort müssen die Schornsteine häufig erneuert werden. Sie 
ragen nur ein kleines Stück über die Bodenoberfläche und werden leicht übersandet, können aber in kurzer Zeit neugebaut werden. - Als nach einem heftigen Regenguß im September 1955 sehr viele Polydora-Schornsteine des Lanice-Wattes vernichtet waren, konnte ich beobachten, daß während des darauffolgenden Hochwassers, d. h. in wenigen Stunden, die Schornsteine neu gebaut waren.

Zusammenfassend können wir beim Röhrenbau von $P$. quadrilobala folgende Arbeitsphasen unterscheiden:

1. Herstellung einer provisorischen Schutzhülle an der Bodenoberfläche, Eingraben ins Sediment, so tief, daß der kiementragende Körperabschnitt darin Schutz findet. Bei diesem Bauabschnitt werden am natürlichen Standort einige größere Sandkörner an der Bodenoberfläche mit Schleim zusammengesponnen.

2. Bau des 1. Schornsteines.

3. Bau und provisorische Auskleidung des U-förmigen Ganges im Inneren des Sedimentes, Schaffung des 2. Ausganges.

4. Bau des 2. Schornsteines.

5. Auskleidung des ganzen Röhrensystẹms mit einer Schleim-Detritus-Tapete und Verlängerung der Schornsteine.

\section{Polydora redeki}

Polydora redeki besiedelt bevorzugt harte Tonböden, wo es zu einer hohen Besiedlungsdichte kommt (60 Schornsteine auf $\left.5 \mathrm{~cm}^{2}\right)$. Die hier untersuchten Tiere stammten aus dem Nord-Ostsee-Kanal.

Länge der über die Bodenoberfläche ragenden Schornsteine: $1 \frac{1 / 2}{\mathrm{~mm}}$. Länge der Röhre: bis $2 \mathrm{~cm}$. Durchmesser der Röhre: $1600 \mu$. Wanddicke: $300 \mu$.

Die beiden Schenkel der U-Röhre verlaufen oft nicht parallel. In dem festen Material sind die eingelagerten Muschelbruchstücke und Pflanzenteile oder etwas größere Sedimentstücke nicht zur Seite zu schieben, sondern müssen von den Tieren bei der Anlage der Wohnung umgangen werden.

Die Röhre ist im Sediment deutlich gegen das Substrat abgesetzt und läßt sich mit einer Nadel herauspräparieren. - In der Röhrenwand sind drei Schichten zu unterscheiden:

Außen wird die Röhre von einer Hülle gebildet, die aus Schleim-Detritusmasse besteht, in die aber größere Tonpartikel, feine Sandkörnchen und manchmal auch Muschelbruchstücke und Pflanzenteile eingelagert sind. Die äußere Schicht ist stark von Eisenoxyd gefärbt. Es folgt eine feiner strukturierté Schicht gleicher Substanz. Den inneren Abschluß bildet meist als Tapete eine glasartige Haut aus erhärtetem Schleim.

Dic Herstellung der Röhren wurde unter dem Binokular beobachtet. In Schalen wurden Tonbrocken gelegt, diese fein zerkleinert und an der Oberfläche pastenartig geebnet, getrocknet und auftretende Trockenrisse wieder mit Ton verschmiert. Das so entstehende außerordentlich feste Substrat wurde den Würmern zum Bohren angeboten, nachdem es kurze Zeit wieder mit Wasser bedeckt war. Tiere, die vorher mehrere Tage im Aquarium gehältert waren, wurden mit einer feinen Nadel vorsichtig aus ihren Röhren herausgehoben und auf dieses Substrat gelegt. Die Würmer hängen mit Schleimbändern sehr fest in ihren Röhren und sind überaus emfindlich. Es wurden nur solche Tiere verwendet, die völlig unbeschädigt waren.

Schon nach einmaligem, ungefähr $1 \mathrm{~cm}$ weitem Vorwärts- und Rückwärtskriechen ist das Versuchstier von einer Schleimhülle umgeben, an der Tonpartikel kleben. Das Vorwärts- und Rückwärtskriechen wird mehrere Male wiederholt. Nach einer Ruhepause von 1-2 Minuten beginnt dann der Wurm 

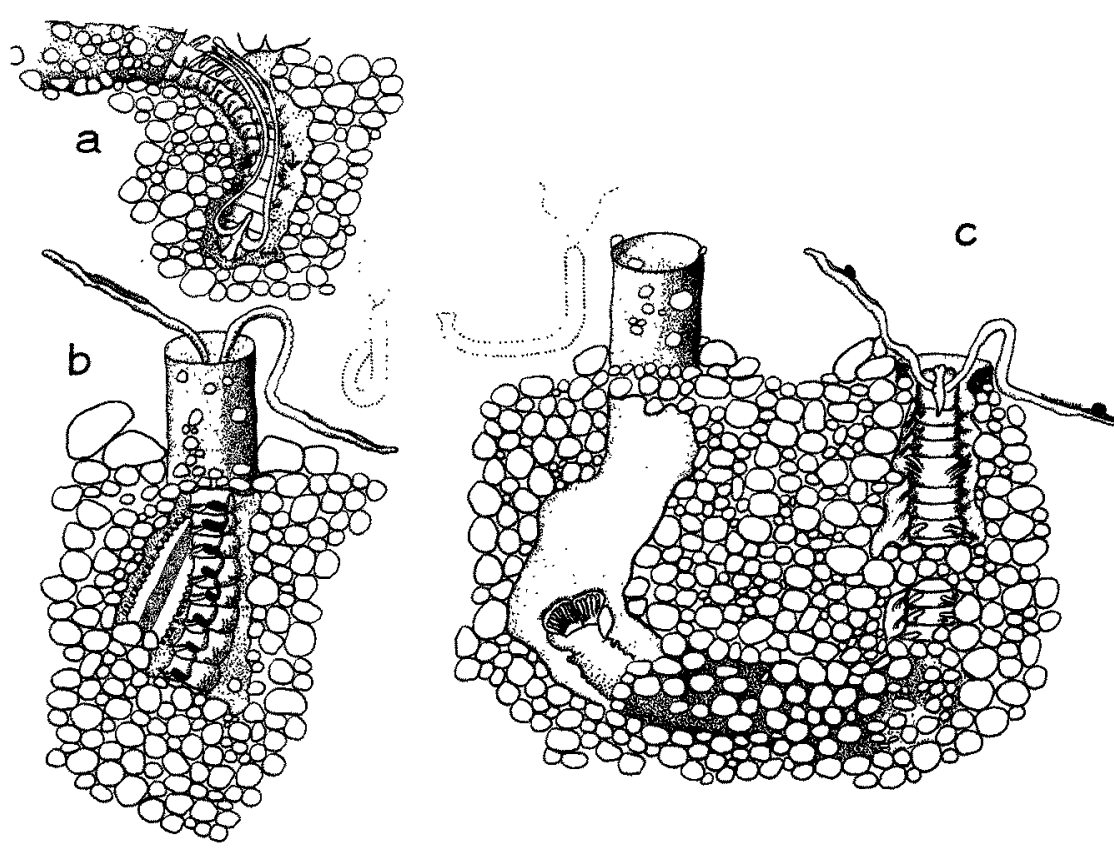

Abb. 5. Röhrenbau von Polydora quadrilobata (schematisch). a) Aus einer Schutzhülle an der Bodenoberfläche, die aus erhärtetem Schleim und einigen daranhaftenden Sandkörnern besteht, schiebt der Wurm sich in das Sandlückensystem der oberflächlichen Schichten. Er scheidet dabei Schleim aus, wodurch ein Nachsickern des Sandes verhindert wird. b) Der Wurm hat sich in der Höhlung umgedreht und baut den ersten Schornstein. c) Der zweite Schornstein entsteht, bevor der Innenausbau des Röhrensystems beendet ist. Die Röhre ist zum Teil aufgeschnitten dargestellt, um den Wurm bei der Arbeit zu zeigen
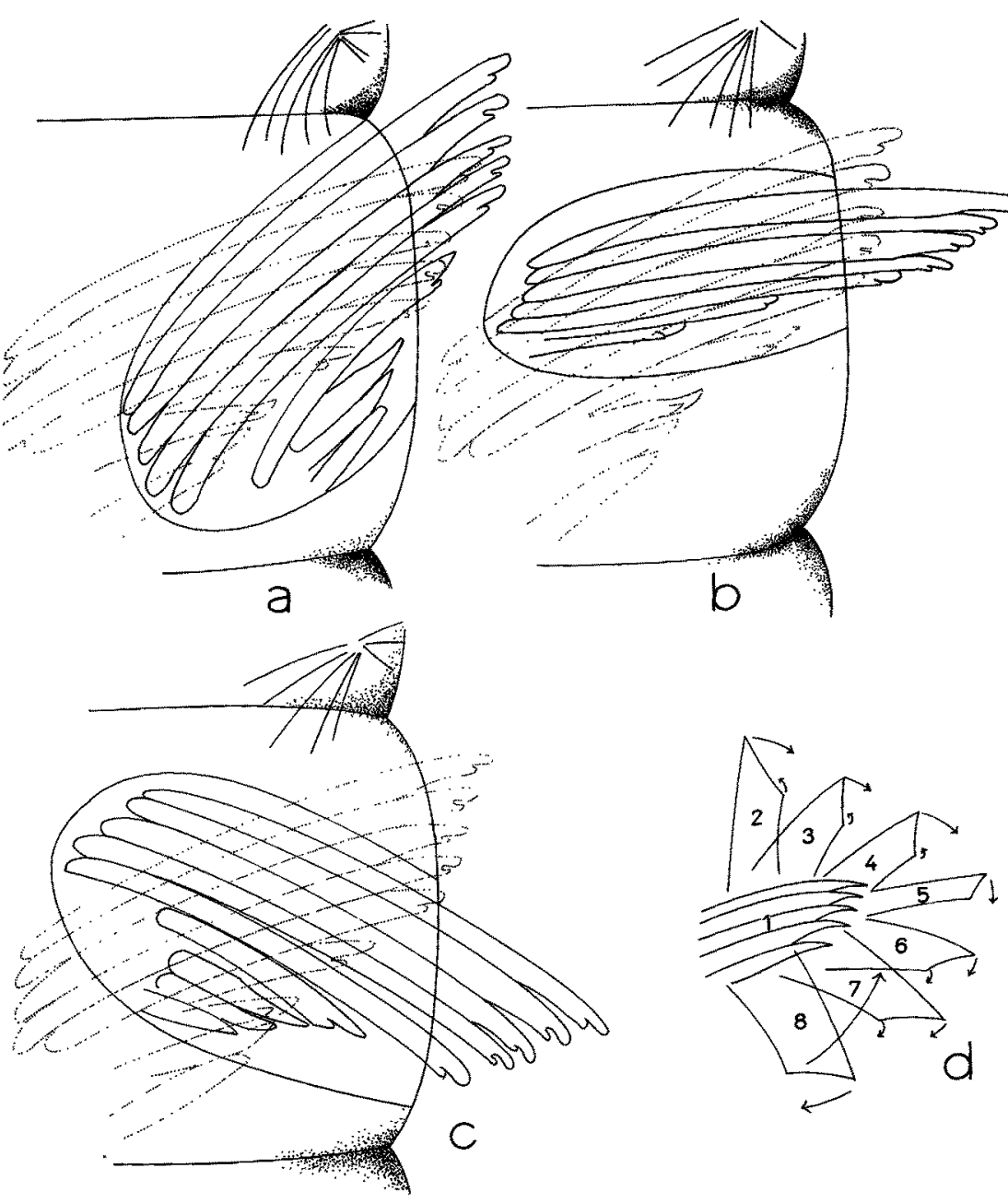

Abb. 6. Bewegungen des Borstenbündels im 5. Segment von Polydora redeki beim Bohren in Ton. a-c) Drei verschiedene Stellungen der Borsten bei der Bohrtätigkeit. Die punktierte Linie gibt die Ruhelage an. d) Bewegung der Borsten bei einer Raspelperiode. 1: Ruhestellung, 2-8: Stellungen bei der Bohrtätigkeit. Die Borsten beschreiben eine in zwei Ebenen halbkreisförmige Bewegung 
viertel-, halbkreisförmige Bewegungen an der Bodenoberfläche auszuführen, wobei die Tonpartikel der Oberfläche zur Seite geschoben werden. Stößt das Tier bei diesen Suchbewegungen auf irgendeine größere Unebenheit in der Sedimentoberfläche, so dient diese als Ansatzpunkt für die Bohrtätigkeit. Die Borsten des fünften Segmentes sind das Hauptwerkzeug zum Eingraben in den Tonboden. Das vollzieht sich in Seitenlage. So-bald eine kleine Vertiefung mit den Borsten geschaffen ist, führt der Wurm bogenförmige Kriechbewegungen aus. Er beschreibt dabei eine nierenförmige Kriechspur. Aber nur bei jeder vierten Hobelperiode wird die Spur ganz beschrieben, die anderen Male kriecht er nach dem Raspeln in der alten Spur rückwärts und setzt gleich wieder zu neuem Hobeln an. Immer an der Stelle der stärksten Bogenkrümmung hobeln die Borsten das Tonmaterial weg Es ist unter dem Binokular deutlich zu beobachten, wie die feinen, losgelösten Tonpartikel im Wasser schwimmend und vom Cilienschlag der Kiemenwimpern aufgewirbelt, langsam an dem Wurmkörper entlangstreichen. Größere Partikel werden häufig unter Spreizen der Borsten irgendeines Körpersegmentes nach hinten oder zur Seite geschoben. Die ganze Grabtätigkeit erfolgt unter ständiger Absonderung von Schleim, so daß das Tier sich bei seinen Bewegungen immer in einer Hülle befindet.

Der Wurm schafft sich so eine bogenförmige Aushöhlung, die schräg in die Tiefe führt. Wenn diese groß genug ist, so daß er mit seinem kiementragenden Körperabschnitt darin Platz findet, tritt eine längere Pause ein. Die Anlage des ganzen Gangsystems und der Schornsteinbau entsprechen im Prinzip der von P. quadrilobata. Der Gang im Sediment wird erst nach Errichtung beider Schornsteine in der ganzen Länge angelegt. Eine genaue Beobachtung der Arbeitsweise der Borsten des fünften Segmentes beim Eingraben in Ton ergab folgendes:

Das Bündel aus je 9 Borsten, die von der Seite gesehen U-hakenförmig angeordnet sind, arbeiten wie eine kleine Schaufel.

Die Muskulatur, die das Borstenbündel bewegt, ist in Abb. 4 dargestellt und in Kap. II beschrieben. Die strahlenförmige Anordnung der breiten Muskelbänder, die von der Borstentasche zu der das Segment umschließenden Ringmuskulatur verlaufen, ermöglicht eine in zwei Ebenen halbkreisförmige Bewegung des Borstenbündels. Die Bewegungen werden ruckartig ausgeführt. Abb. 6a-d geben eine schematische Darstellung der Arbeitsweise der messerartigen Borsten.

Beim Bauen im Aquarium lag der Gang ziemlich an der Oberfläche. Das wird damit zu erklären sein, daß der Wurm wegen des starken Lichtes der Beobachtungslampe oder wegen anderen nicht auszuschaltenden ungünstigen Lebensbedingungen das Bestreben hatte, möglichst schnell in das Sediment einzudringen. Ein flacher Gang beansprucht nicht so viel mechanische Kraft wie ein in die Tiefe führender und ist infolgedessen schneller zu bauen. (Diese Beobachtung entspricht dem Verhalten von $P$. quadrilobata bei Versuchen, in denen als Substrat Feinsand angeboten wurde [s. S. 105].)

Bei $P$. redeki gelang es nicht, den ganzen Bauvorgang unter dem Binokular zu beobachten. Der Bau eines Gangsystems wurde von langen Ruhepausen unterbrochen. Die Tiere starben meist vor Beendigung des Baus. Die Anlage des Ganges und der Baubeginn des zweiten Schornsteines wurde an mehreren Tieren beobachtet, die, nachdem sie auf Tonmaterial gesetzt waren, zunächst einige Stunden im Dunkeln kühl gehalten waren. Die Gänge waren 
dann etwas tiefer als diejenigen, die unter dem Binokular gebaut waren. Insgesamt wurden alle Phasen des Baus fünfmal beobachtet, sie verliefen alle annähernd in der gleichen Weise.

\section{Polydora ligni}

Polydora ligni besiedelt sehr verschiedene Substrate. Diese Art bohrt sich in Tonböden ein und tritt stellenweise in dichten Kolonien in Sand- und Weichböden auf.

Länge der über die Bodenoberfläche ragenden Schornsteine: $2 \mathrm{~mm}$. Länge der Röhre: unterschiedlich, bis zu $4 \mathrm{~cm}$. Durchmesser der Röhre: $1200 \mu$. Abstand der Schornsteine voneinander: ungefähr $5 \mathrm{~mm}$. Die Bautätigkeit und Struktur der Röhre von $P$. ligni ist sehr ähnlich der von $P$, redeki.

Bei dieser Art gelang es, den Bau im Inneren des Sedimentes im Aquarium zu beobachten. Die äußere Schicht der Röhre entsteht auf folgende Weise: Hin- und herkriechend scheidet der Wurm Schleim aus, auf dem das umliegende Tonmaterial haften bleibt. Beim Bewegen in der so entstandenen Hülle scheidet der Wurm auch weiterhin Schleim ab. Die sehr feinen Tonpartikel, die diesem Schleim beigemengt sind, waren, wie ein Versuch mit gefärbten Partikeln zeigte, mit dem Atemwasserstrom in die Röhre gelangt. Die von $P$. ligni im Aquarium gebauten Gänge waren wie bei $P$. redeki sehr flach.

\section{Polydora ciliata}

Die Wohnröhren von Polydora ciliate kommen in sehr verschiedenen Sedimenten des Meeresbodens, angeheftet an Steinen und zwischen Algen vor. Hauptsächlich findet man sie in kleine Vertiefungen eingebettet, die der Wurm in Kalkstein und Molluskenschalen oder andere Kalksubstanzen gebohrt hat.

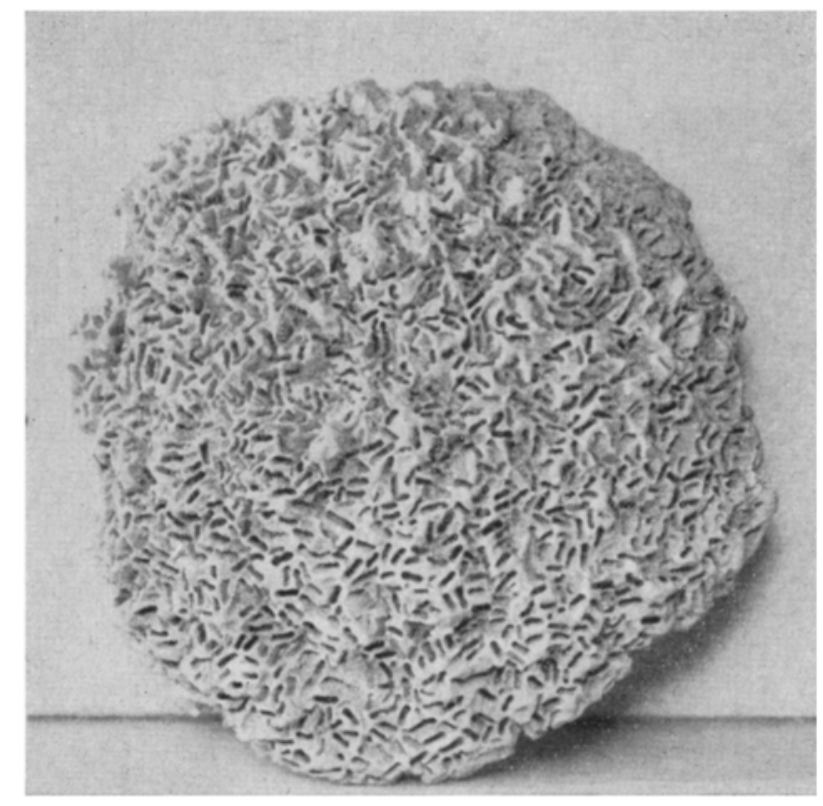

Abb. 7. Von Polydora ciliata zerbohrter Kalkstein aus dem Geschiebe von Suhrendorf

Eine gute Beschreibung der Bohrlöcher und des darin liegenden Röhrensystems gibt PrELL (1925) an Hand eines Helgoländer Kalksteines. Dicht 
nebeneinander liegen an der Oberfläche des Steines kleine hantelförmige Löcher (Abb. 7). Wo der Stein nicht so dicht besiedelt ist, führen zwei flache Spuren bogenförmig zu der Bohrung hin. Zwei runde Offnungen werden von einer 0,2-0,5 $\mathrm{mm}$ breiten Brücke getrennt. Im Querschnitt ist die Wohnhöhle U-förmig und verläuft $5-10 \mathrm{~mm}$ senkrecht oder wenig schräg in die Tiefe. Bei den größeren Vertiefungen sind bogenförmige Linien zu erkennen, welche als Zuwachsstreifen aufzufassen sind. In dieser Höhlung eingebettet liegt die Röhre. Über die Gesteinsoberfläche ragen die Schornsteine $0,5-3 \mathrm{~mm}$ heraus. Das Baumaterial für die Schornsteine kann je nach dem umgebenden Material

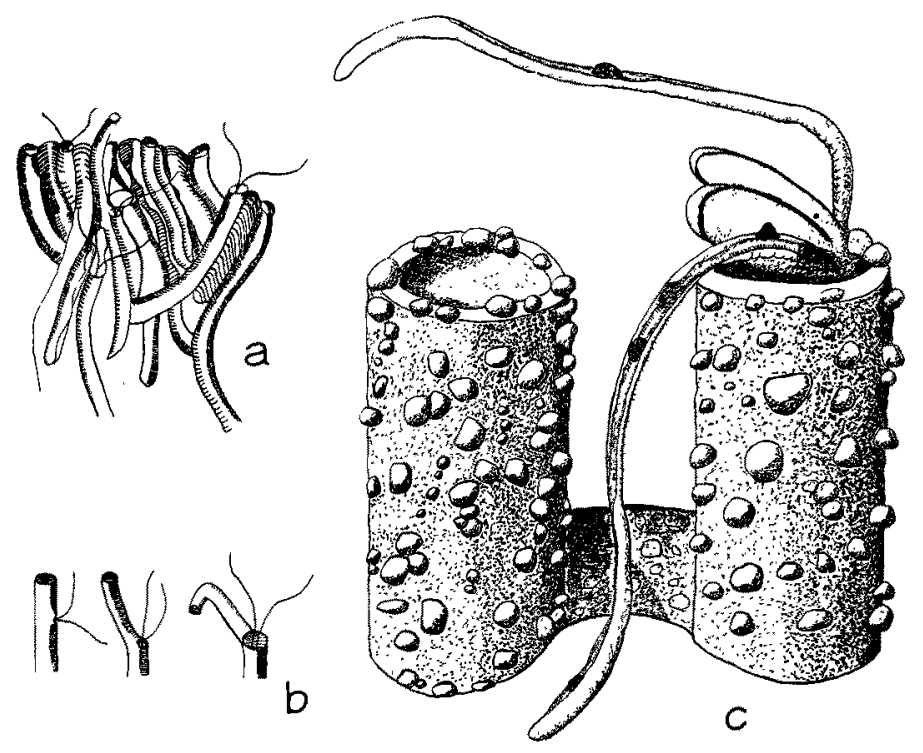

Abb. 8. Röhrensystem von Polydora ciliata. a) Röhrenkolonie; in einer leeren Mytilus-Klappe aus Detritus gebaut. b) Schornsteinverkürzung. c) Schornsteinbau. Der Wurm verbaut mit dem über den Schornsteinrand gelegten Prostomium das Baumaterial, das die Tentakeln herbeibefördern

sehr verschieden sein. Die beiden in der Höhlung liegenden Schenkel des U werden von einer Wand, die oben als Brücke erschien, getrennt. Röhren und Trennungswand bestehen aus feinen Fremdkörpern, wie Sandkörnchen, Detrituspartikeln und Kalksteinsplittern, die durch erhärteten Schleim aneinandergekittet sind. In der Tiefe des Bogens fehlt die Auskleidung manchmal. - Die trennende Mittelwand zeigt oft eine Schichtung, die, wie die oben erwähnte Skulpturierung, auf verschiedene Arbeitsphasen des Wurmes schließen läßt. Bei trockenen Steinen ist sie häufig zerrissen oder die Auskleidungsmasse fehlt ganz. In Molluskenschalen sind die Bohrlöcher und Gänge meist sehr unregelmäßig gestaltet, da die einzelnen Schichten der Schalen den Würmern beim Bohren sehr verschiedenen Widerstand entgegensetzten, oder das Wirtstier, wenn der Polychät beim Bohren die Schale nach innen hin zu durchdringen droht, mit Kalkabsonderung reagiert. Dann muß sich der Wurm einen neuen Ausgang suchen. Der Grundplan des U-förmigen Ganges ist aber auch in den Molluskenschalen gut zu erkennen.

Bauen in lockerem Sediment und Einbau der Röhren in Kalksubstanzen:

Die von $P$. ciliata in verschieden feinem Seesand gebauten Röhren stehen nicht wie die von $P$. quadrilobata senkrecht im Boden, sondern liegen waage- 
recht auf der Sedimentoberfläche oder verlaufen in einem kurzen Bogen dicht unter der Oberfläche. Trotzdem entsprechen sie in Struktur und Anlage der Schornsteine und der Röhre dem allgemeinen Typ der U-förmigen PolydoraRöhre.

Die Schornsteine können sehr unterschiedlich lang und sehr verschieden stabil sein. Auf Littorina-Schalen in der Brandungszone z. B. ragen sie manchmal weniger als $1 \mathrm{~mm}$ über das Bohrloch hinaus. Zwischen dem Algenaufwuchs und Balanidenschildern auf einer Muschel schale sind sie mehrere Millimeter lang (Abb. 8a). Bei anderen Kolonien, die oft aus Mudd gebaut, zwischen dem Byssusgespinst von Mytilus zu finden sind, kann man überhaupt nicht zwischen Röhre und Schornstein unterscheiden.

Wenn der Schornstein beschädigt ist, werden zur Reparatur oft große Sandkörner angebaut, die dem Wurm zunächst Schutz bieten. - Bei günstigem Angebot von Baumaterial scheinen die Tiere neben der Nahrungsaufnahme ständig an dem Röhrensystem weiterzubauen. Haben die Schornsteine eine bestimmte Länge erreicht, werden sie, besonders wenn aus Mudd gebaut, instabil und von dem Polychäten selbst wieder verkürzt. (Abb. 8b.) Der Wurm schiebt seitlich seine Tentakeln durch ein Loch in der Schonsteinwand, welches an einer instabilen Stelle mittels Druck mit dem Prostomium entstanden ist. Er drängt sich mit dem ganzen vorderen Körperabschnitt durch dieses Loch heraus, schiebt das obere Schornsteinende zur Seite und benutzt die Offnung zum neuen Röhrenausgang.

Wie die Würmer ihre Röhren in gebohrten Höhlungen herstellen, wurde beim Bau in aufgespalteten Austernschalen und Schneckenhäusern (Littorina und Buccinum) beobachtet. In welcher Reihenfolge die einzelnen Röhrenabschnitte gebaut werden. untersuchte ich mit ver schieden gefärbtem, nacheinander angebotenem Sand.

Auch bei dieser Art wird der Schornsteinbau (Abb. 8c) vor der Auskleidung des Bohrloches im Inneren der Muschelschale ausgeführt. Die im Bohrloch eingebettete Röhre besteht aus wesentlich gröberem Material, das weniger sorgfältig aneinandergefügt ist, als in den Schornsteinen. Die Stabilität der Röhre nimmt nach unten hin ab. Die Wand zwischen den beiden Schenkeln entsteht teils vor, teils während des Röhrenbaus.

\section{Das Bohren von Polydora ciliata}

\section{Historische Öbersicht und Problemstellung}

Schon 1670 (veröffentlicht 1737) meldet Swammerdamm den Fund von Littorina-Schalen, die von kleinen Würmchen zerfressen sind. Für die englischen und französischen Steilküsten und die Kreide bei Helgoland werden dichte Siedlungen von Polydora ciliata beschrieben. Zwischen Somme und Seine leben im Kalkstein bis zu 250000 Individuen auf $1 \mathrm{~m}^{2}$. $P$. ciliata ist zahlreich vertreten in den Lagunen und seichten Buchten bei Triest. Die venezianischen Austernfischer schen Polydora-Befall als eine Hauptgefahr für die Muschelbänke an. (CARRAZI 1895.) WhitelegGe (1890), der P. ciliata an der australischen Küste bei New-Castle beobachtete, vermutet, daß ihre Larven sich ohne zu bohren an der Schaleninnenseite festsetzen und eine Schlammröhre bauen, um die der Wirt auf den Reiz hin, eine Kalklamelle abscheidet.

ANDrews (1891) beschreibt $P$. ciliata als Kommensalen. Er fand den Polychäten vergesellschaftet mit Hydractinia auf einem Schneckenhaus, das von einem Einsiedlerkrebs bewohnt war.

Auch im Geschiebe und Angespül unserer Küsten, vor allem auf der Düne von Helgoland, und in Dretschfängen, finden sich Kalksteine und Molluskenschalen, die filigranartig von Polydora-Gängen durchzogen sind. Die Austern- und Mytilis-Bänke der Nordseeküste und die Pfähle der Kieler Bucht sind von diesen Epibionten besiedelt. Befallene Balanidenkolonien mancher Strandbefestigungen können in kurzer Zeit zu Bruchschill aufgearbeitet und die Littoriniden völlig zerfressen sein.

Die Vielseitigkeit der geologischen Fragestellung, die mit der Bau- und Bohrtätigkeit von Polydora verbunden ist, wird in einem besonderen Kapitel behandelt.

Die Fähigkeit, sich in Kalksubstanzen einzubohren, war für $P$. ciliata seit langem bekannt. Es handelt sich um ein weitverbreitetes Phänomen, das auch von wirtschaftlicher Bedeutung ist. Wie stellt der Wurm die Bohrlöcher her? Dies Problem war bisher noch ungelöst. 
Es wurde zwar des öfteren zu dieser Frage Stellung genommen. Experimente und Beobachtungen an bauenden und bohrenden Würmern liegen jedoch fast gar nicht vor. Nur SöDERSTRöm (1923) berichtet von einigen Beobachtungen an lebenden Tieren. Die übrigen Autoren geben eine kurze Beschreibung der Bohrgänge und des Röhrensystems und schließen von deren Formen und der Struktur des angebohrten Materials auf die Bohrweise der Würmer.

Für das Zustandekommen der Bohrlöcher gibt es drei Möglichkeiten:

1. Die Bohrlöcher werden auf mechanische Weise hergestellt.

(MeCZNikow, 1865; LANKester, 1868; MC. Intosh, 1915.)

Mc. Intosi und Mecznirow fanden P. ciliata in säureunlöslichem Gestein, wo also eine chemische Bohrweise nicht in Frage kommt. Als Werkzeug für eine mechanische Bohrarbeit sind die Borsten des fünften Segmentes anzunehmen. Carazzi erwähnt für $P$. armata und P. hoplura die besonders stark entwickelten Borsten der hinteren 10 Segmente. Diese beiden felsbohrenden Arten sind im Mittelmeergebiet verbreitet.

2. Die Bohrlöcher werden chemisch mit Hilfe einer Säure hergestellt.

(LANKESTER, 1868; SöDERSTRÖM, 1923.)

Hauptsächlid sprechen die von LANkester und Söderström geführten Nadhweise (Lakmus und Vitalfärbung mit Neutralrot) einer sauren Reaktion der Schleimdrüsensekrete für eine chemische Bohrtätigkeit. Nach PRELL (1925) kommt als ätzende Säure nur die ständig im Stoffwechsel anfallende Kohlensäure in Frage. Schwefelsäure scheidet aus, denn neben feinen Quarzkörnchen werden auch Kalkpartikel in die Gangverkleidungen mit eingebaut. Da der Wurm mit dieser in Berührung kommt, müßten sie in Gips verwandelt werden, was aber nicht der Fall ist.

$Z$ u dem Vorkommen von $P$. ciliata im Helgoländer Sandstein sagt Söperström, daß es sich bei diesem zwar stratigraphisch um Sandstein, petrographisch aber um kalkigen Mergel handele. Das Gestein ist in der Brandungszone stark ausgelaugt und setzt dem Wurm mechanisch nur wenig Widerstand entgegen. Die Gänge sind dort jedoch eng-schleifenförmig, wie immer, wenn den Würmern ein starker Widerstand entgegengesetzt wurde (LANKEsTER). Dieser Widerstand müßte chemischer Art sein.

3. Der Wurm arbeitet chemisch mit Hilfe einer Säure und auch mechanisch mit Hilfe der Borsten des fünften Segmentes.

(Carazzi, 1895; Söderström, 1920; Prell, 1925; Hannerz, 1956.)

Einerseits läßst das Vorhandensein eines zum Bohren brauchbaren Werkzeuges auf eine mechanische Herstellungsweise der Höhlungen schließen, andererseits weist die Exkretion einer Säure auf die Möglichkeit einer chemischen Bohrweise hin. So kommen verschiedene Autoren zu dem Schluß, daß es sich bei der Bohrtätigkeit von $P$. ciliata um eine Kombination beider Arbeitsweisen handele. HanNerz fand an metamorphosereifen Larven (17 bis 20 Segmente) ventral von den Borsten des fünften Segmentes, Drüsen, die mit den Borstentaschen in Verbindung stehen und die nach der Metamorphose rückgebildet werden.

Er wies für diese Drüsen ein saures Sekret nach und vermutet, nach Beobachtungen an Larven, daß die erste Arbeit teilweise chemisch geleistet wird, während die erwachsenen Tiere dann möglicherweise mechanisch bohren.

In den folgenden Kapiteln werden Aquarienbeobachtungen an adulten Tieren, genaue Untersuchungen des angebohrten Materials und des Bohrwerkzeuges geschildert, die für eine rein mechanische Bohrweise von adulten $P$. ciliata sprechen.

\section{Beobachtungen an dem von Polydora angebohrten Material}

a) Verzeichnis der angebohrten Molluskenschalen

Bei folgenden Mollusken fand ich Bohrspuren von P. ciliata sowohl in den leeren als auch in bewohnten Schalen und Gehäusen. Die einzige Aus* 
nahme bildet Mya arenaria. Diese Art scheint der Wurm nur postmortal zu befallen. Allein dort, wo sie als Bankmuschel lebt, also nicht eingegraben im Sediment, ist sie mitunter schon zu Lebzeiten angebohrt. (Mündl. Mitteil. JÄCKEL.)

Ostrea edulis $\mathrm{L}$

Cardium edule $\mathrm{L}$.

Mytilus edulis $\mathrm{L}$.

Littorina littorea $\mathrm{L}$.

Mya arenaria L.

Buccinum undatum $\mathrm{L}$

Scrobicularia plana Da Costa

In der Literatur wird von einigen weiteren Mollusken-Arten Polydora-Befall erwähnt:

ANkel 1936: Gibbula cineraria L., Littorina obtusata L., Nucella lapillus L., Langerhans 1886: Pinna L. Elrason 1920: Neptunea antiqua L. Hannerz 1956: Palella vulgata L.

b) Lage der Bohrlöcher auf der Schale

Zuerst und am dichtesten werden auf den Schalen und Gehäusen die skulpturierten Stellen befallen.

Bei Littorina und Buccinum liegen die feinen Löcher oft dicht nebenein-
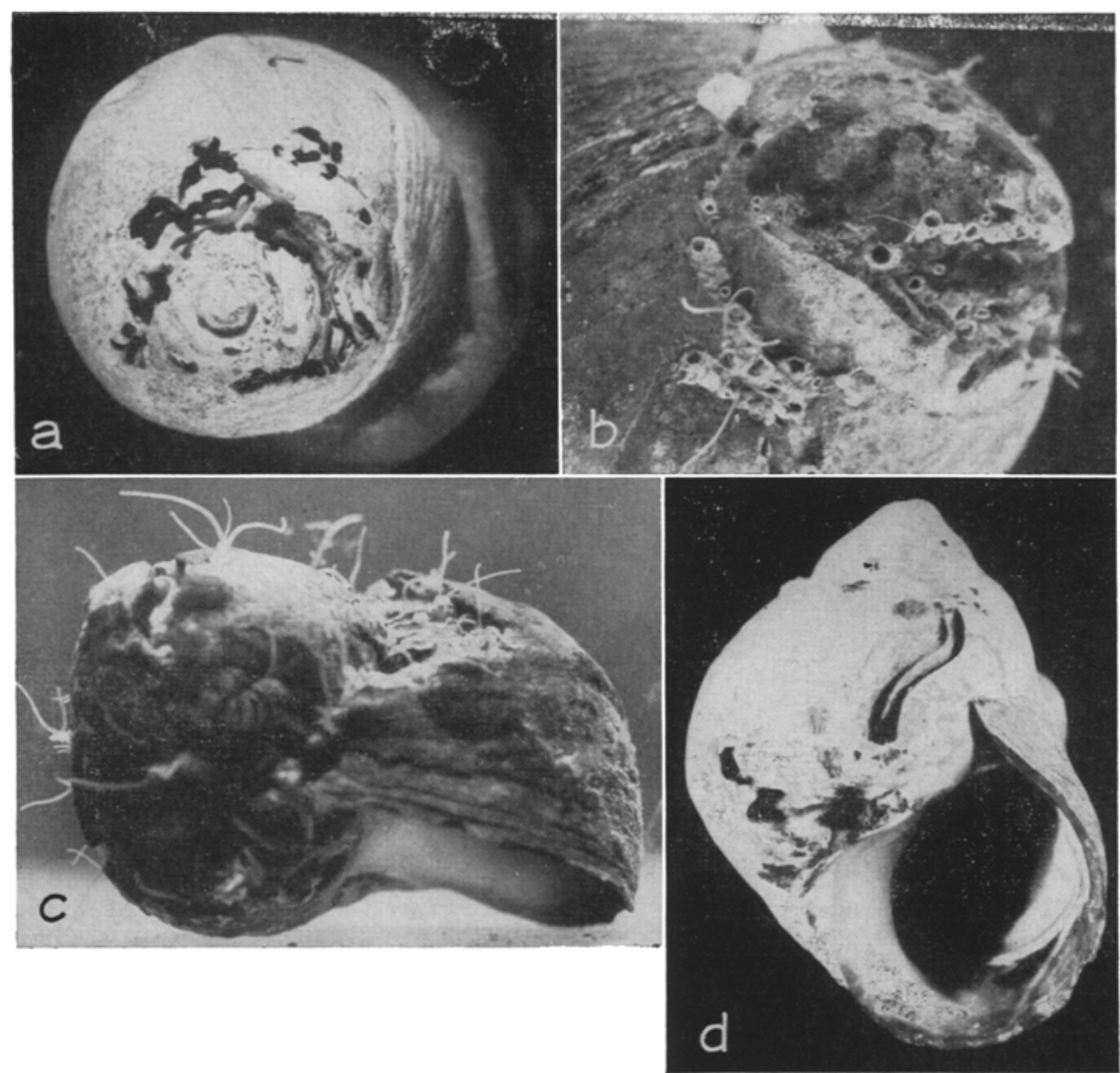

Abb. 9. Bohrspuren von Polydora ciliata in Littorina littorea. a) Die Region des Apex wird besonders in den Nähten stark zerbohrt. b) Ausschnitt aus der Region des Apex. Die Abbildung zeigt verschieden große Schornsteine und Bohrspuren, z. T. mit herausragenden Tentakeln. Einige Würmer kommen, durch Formalin gereizt, mit dem ganzen Vorderende aus ihrem Röhrensystem heraus, c) Polydora ciliata auf Littorina. d) Langer, schleifenförmiger Bohrgang, die Röhre wurde aus dem Gang entfernt 
ander in den Nähten. Bei fortgeschrittenem Befall kann der ganze Apex zerfressen oder abgefallen sein (Abb. 9a u. b).

Bei ausgewachsenen Mollusken findet man Bohrlöcher auch in den Anwachsstreifen, am Collumellarand und am Nabel. Wenn an einer der skulpturierten Stellen eine größere Anzahl von Polydoren ihre Gänge angelegt hat, greift der Befall oft auf das ganze Schneckenhaus über (Abb. 9c). Bis ins Innere des Gehäuses dringen die Bohrlöcher nur selten ein (Abb. 9d), da die Schnedke den mechanischen Reiz, den der bohrende Wurm ausübt, mit Kalkabsonderung an der gefährdeten Stelle beantwortet. Beschädigungen am Columellarand kommen sehr selten vor und werden nach TAUBER (1944) vom Mantelrand ausgebessert. Solche Stellen sind an etwas verzerrten Anwachsstreifen zu erkennen.

Nach Ankel wohnt fast immer ein Wurm in dem Nabel von Gibbula cineraria. - Bei den übereinandersitzenden Pantoffelschnecken sind der untere Rand, mit dem ein Tier auf dem anderen sitzt, und der Wirbel die bevorzugten Regionen.

Unter den Muscheln sind die Austernschalen am häufigsten und dichtesten befallen. Die obersten Lamellen sind bei diesen stark gewellt und mit Knötchen besetzt und bieten so den Würmern gute Ansatzpunkte. Bei Mytilus zeigt die Gegend des Schlosses und die am stärksten gewölbte Region die meisten Bohrspuren. Bei mehreren Exemplaren von Cardium fand ich die kleinen Offnungen der Bohrgänge nur in den Rippeln am Rande, andere Artgenossen hatten sie allein am Schloß. Nur die Schale von Mya arenaria ist ganz vorwiegend auf der Innenseite angebohrt. Bei allen anderen erwähnten Molluskenarten wird die Schalenaußenseite bevorzugt, auch wenn der Wurm die Schale erst postmortal befallen hat.

Für den Zeitpunkt des Befalles mit Polydora spielt die Lebensweise des Mollusken eine ausschlaggebende Rolle, wie TAUBER an einem umfangreichen fossilen Material aus dem Torton des Wiener Beckens und rezenten Molluskenschalen zeigte. Prämortal sind am häufigsten sessile Mollusken angebohrt, dann folgen vagile nicht grabende und vagile gelegentlich grabende Arten. Ausschließlich grabende Mollusken zeigen vor dem Tod des Weichtieres auf ihren Schalen fast nie Bohrspuren von P. ciliata.

Für die Bevorzugung der skulpturierten Stellen bei der Bohrtätigkeit kann es zwei Gründe geben:

1. In den Nähten, Ritzen und zwischen den gewellten Lamellenblättern finden die Larven den ersten Schutz. Unter dem Binokular konnte beobachtet werden, wie die Larven auf der Molluskenschale herumkrochen oder schwammen, bis sie kleine Vertiefungen oder einen Spalt gefunden hatten, in den sie hineinschlüpfen konnten. Das gleiche gilt für adulte Tiere, die zum Verlassen ihrer Röhren veranlaßt wurden.

2. Die skulpturierten Abschnitte sind gleichzeitig diejenigen, an denen sich beim Wachstum des Kalkteiles der Schale die organische Schalenaußenhaut, das Periostracum zuerst ablöst. Nach KıöHN (1936) werden diese Stellen auch am stärksten vom Seewasser chemisch beansprucht. Er wies eine starke „Kreidigkeit", z. B. für die Rippeln am unteren Rand einer Cardium-Schale und die Region des Wirbels bei verschiedenen Molluskenschalen nach. Durch die chemische Arbeit des Wassers wird die Oberfläche der Molluskenschalen in ein feines Maschenwerk zerlegt. Der Wurm ist aber auch im Stande, das 
Periostracum zu durchbohren, wie z. B. an jungen Littorina-Schalen zu beobachten ist.

c) Die Bedeutung anderer Epibionten für die Bohrtätigkeit von Polydora ciliata

Die Schalen besonders der adulten Mollusken werden von zahlreichen Epibionten bewohnt, welche für die Polydora-Larven zum Teil günstige Ansatzmöglichkeiten schaffen.

Oft sind die Schalenaußenflächen fast völlig von Bryozoen bewachsen (Abb. 10). Dazwischen siedeln Balaniden, Polypen, Schwämme, Algen usw. Ein Bild von der Mannigfaltigkeit der Formen, denen Prosbranchier als Wirte dienen, gibt ANKEL.

Unter diesen Epibionten gibt es eine ganze Reihe von bohrenden Arten. Ätzschwämme (Glionidae) und manche Bryozoen (Marcus 1926) sind kalklösend und minieren die Schalenoberfläche. Auch einige andere Polychätenarten bohren sich in Muschelschalen und Schneckenhäuser ein: Dodecaceria

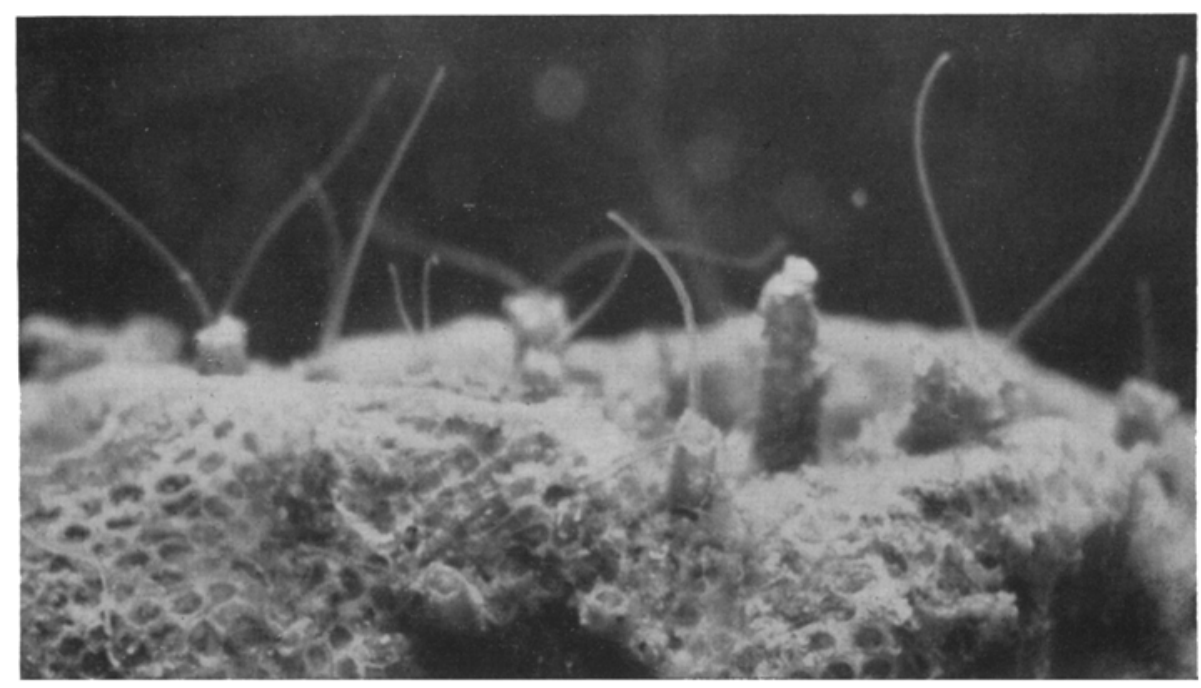

Abb. 10. Polydora-Kolonie auf einer Austernschale, die von Bryozoen überwachsen ist

concharum Oerstedt (häufig in den Austernschalen der Lister Austernbänke) und Potamilla reniformis O. F. Müller. - Durch die Bohrtätigkeit dieser Organismen, die v. PIA (zit. bei Wetzel 1937) als wichtigste Zerstörer der leeren Molluskenschalen angibt, wurden Prismen der obersten Schichten gelockert und für die nachfolgenden mechanischen und chemischen Angriffe des Wassers neue Ansatzpunkte geschaffen. Wетzé beschreibt sehr regelmäßiges Vorkommen mikroskopischer Bohrorganismen in Schillansammlungen, Austern- und Mytilus-Bänken der Flachsee und in den Mollusken der Steilküsten und Felsgründe in Gegenwart und erdgeschichtlicher Vergangenheit. (Seit dem Silur bekannt.)

Unter fünfzig Austernschalen von den Austernbänken vor List fand ich ungefähr vierzig mit ganz deutlicher von Cyanophyceen hervorgerufener Färbung (grünlich oder bräunlich). Auch bei den meisten anderen Molluskenarten 
war die Oberfläche fast immer von Blaualgen durchsetzt. Folgende bohrende Algen wurden auf den Molluskenschalen gefunden ${ }^{5}$ ).

\author{
auf Buccinum undatum:
}

auf Crepidula:
Perforierende Algen

Cyanophyceen

1. Plectonema terebrans Born et Flak.

2. Hyella caespitosa Born et Flak.

Chlorophyceen

1. Gomeritia polyrhiza Born et Flak.

2. Ostrobium Queketti Born et Flak.

1. Plectonema terebrans

2. Hyella caespitosa

3. Mastigocoleus testarum Lagerheim.

Chlorophyceen wie oben.

auf Mytilus:

vorwiegend Ostrobium Queketti. vereinzelt Plectonema terebrans.

auf Cardium:

überwiegend Gmeritia polyrhiza. fast keine Cyanophyceen.

Andrerseits gibt es auch eine Menge Epibionten, durch welche die Polydora-Kolonien vernichtet werden können. Von Einsiedlerkrebsen bewohnte Prosobranchiergehäuse werden sehr oft von dem Hydroidpolypen Hydractinia echinata Flem. oder Podocoryne carnea Sars befallen. Als dicke Kruste mit stacheliger Oberfläche (ANKEL) überwachsen sie das Schneckenhaus. Die Kalksubstanz wird teilweise resorbiert (AURIvillus 1891). Löst man mit einem Messer den Polypenbelag ab, so findet man in der Schale vielfach die Bohrgänge von $P$. ciliata, die vor dem Polypenbefall angelegt und später erstickt wurden. Auch der Schwamm Halichondria panicea, der meist auf Mytilus lebt, kann einen so dichten Bewuchs bilden, daß darunter $P$. ciliata abstirbt.

d) Die prismatische Struktur der Molluskenschalen

Bei den Schalen der Meeresmollusken sind bei Schliffen senkrecht zu den Anwachsstreifen drei ihrer Struktur nach verschiedene Schichten zu unter.scheiden. Auf das bei älteren Tieren meist beschädigte Periostracum folgt die Kalkschicht (porzellanartige Schale) und als innerer Abschluß bei den älteren Molluskenfamilien die Perlmutterschicht.

Die scheinbar homogene Porzellanschale setzt sich aus mehreren, meist drei Schichten zusammen. Sie ist aus kristallinen Kalkfibrillen aufgebaut, die Kalkplatten bilden. Die Schichten sind gegeneinander geneigt $\left(75-105^{\circ}\right)$, wodurch im Anschliff eine vielfältige Anordnung erscheint. Senkrecht nebeneinander stehende Prismenplatten wirken wie Palisaden. Wenn zwei Platten in einem Winkel von $70^{\circ} \mathrm{bzw} .110^{\circ}$ aufeinander folgen, erscheinen sie, da durchsichtig, im Schnitt wie ineinander verflochten. $Z u$ unterscheiden sind Balkenanordnung, Palisadenstruktur und Gitterstruktur. Außer den Unterschieden in der Streichrichtung können die Prismen auch verschieden dicht gepackt und besonders in der obersten Schicht wie "auseinandergebogen" erscheinen (BøGGILD 1930, ANKEL 1936).

$\mathrm{Da}$ die einzelnen Bauelemente der Schale den Würmern, die sich zunächst von der Oberfläche senkrecht in die Schale einbohren, verschieden starken Widerstand entgegensetzen, wurde die Schalenstruktur der Mollusken, die von $P$. ciliata befallen werden, im Anschliff untersucht. Die Anschliffe zeigten bei allen von Polydora besiedelten Arten in den angebohrten Schichten eine locker-federige, palisadenartige oder schwach geneigte Struktur.

5) Für die Bestimmung der Algen danke ich Frl. D. Aldinger. 
e) Die chemische Zusammensetzung der Molluskenschalen

Die Schalen der Meeresmollusken bestehen im allgemeinen aus 95-98 \% Calciumcarbonat, entweder in Form von Calcit oder von Aragonit und ungefähr 1,5\% Conchyolin. Conchyolin ist eine organische Substanz, die das bereits erwähnte Periostracum bildet.

Sowohl in der Härte, als auch in der Säurelöslichkeit besteht ein Unterschied zwischen Calcit und Aragonit.

Calcit: Härte 3, geringe Säurelöslichkeit.

Aragonit: Härte $3 \frac{1}{2}$, größere Säurelöslichkeit.

Demnach wäre der Calcitanteil leichter mechanisch, der Aragonitanteil leichter chemisch zu bearbeiten.

Für die Unterscheidung dieser beiden Modifikationen des Calciumcarbonates gibt es verschiedene Methoden. Die Trennung nach der Härte ist sehr schwierig, da diese je nach der Lage der Kristalle etwas variabel ist. Ich führte die Trennung nach der Meigenschen Probe durch ${ }^{6}$ ).

Feine aus der Molluskenschale herauspräparierte Stücke wurden pulverisiert mit Kobaltnitrat erhitzt. Aragonit wird nach kürzester Zeit violett, Calcit nach langem Kochen blaugrün.

Diese Probe ergab, daß von den bohrenden Polydoren der Calcitanteil, d. h. der mechanisch leichter angreifbare Teil, bevorzugt wird, wie Häufigkeit und Größe der Gänge zeigen.

Ostrea edulis, die am häufigsten befallene Art, ist ein reiner Calcitschaler. Die Littoriniden haben eine dicke äußere Calcitschicht.

\section{f) Der Kalkstein}

Kalk- und Kreideablagerungen der Triasformation, und zwar sowohl anstehende Transgressionsflächen als auch losgelöste Felsbrocken werden häufig von $P$. ciliata angebohrt (Abb. 7). Auch in Kreidebändern, die in Feuersteinen eingelagert sind, findet man Polydora-Gänge. Bei schwacher Verkieselung des Gesteins wird Polydora selten und fehlt bei stärkerem Auftreten von Kieselsäure ganz.

Die Oberfläche des Gesteins wird durch mechanische und chemische Kräfte in gleicher Weise aufgearbeitet, wie die Molluskenschalen. Die Besiedelung mit Epibionten ist bei den Kalksteinen nicht so stark wie bei den Molluskenhartteilen. Als bohrende Arten treten am häufigsten Blaualgen auf, die an den Steilküsten oder auf Geschiebeblöcken dichte Überzüge bilden können und sich zwischen die Prismen schieben. Dadurch kann die submikroskopische Struktur der Gesteinsoberfläche netzartig aufgelöst werden.

Nach Prell werden, abgesehen von Kalk- und Kreidegestein, von den Würmern auch Töckschiefer und diluvialer Süßwasser-Töck besiedelt. Nach RICHTER (1924) sogar triassische Tonsandsteine. In Buntsandstein dringen die Tiere nach SöDERSTRöM (1923) gewöhnlich nicht oder nur an angewitterten Stellen ein. Prell fand Polydora bei Helgoland auch in "erweichtem" Sandstein (s. S. 111).

\section{Versuche zur Bohrtätigkeit von Polydora ciliata}

Um Polydora ciliata direkt bei der Bohrtätigkeit zu beobachten, wurdem zahlreiche Aquarienversuche durchgeführt. Da sowohl Larven, die aus Planktonfängen stammten, als

9) Herrn Prof. Wetzel danke ich für freundliche Hinweise zur Methodik dieser Untersuchungen. 
auch adulte Tiere, die vorsichtig zum Verlassen ihrer Röhren veranlaßt wurden, im Aquarium sehr schnell starben, setzte ich Zuchten an:

Zahlreiche P. ciliata, die in Muddröhren an Mytilus gesiedelt hatten, wurden mit ihren Röhren vorsichtig von den Muscheln gelöst. In großen gut durchlüfteten Aquarienbecken auf eine $10-15 \mathrm{~cm}$ dicke Schicht von gründlich ausgewaschenem feinem Seesand gelegt, hatten sie sich schon nach einigen Tagen in Verlängerung der Muddröhre im Sand eine neue Röhre gebaut. Die Zuchten wurden zweimal in der Woche mit einer feinen Aufschwemmung von Piscidin (Präparatenfabrik Haberle, Körnung 000) gefüttert und das Wasser alle zwei Monate erneuert. Auf solche Weise gehälterte Tiere wurden zu den anschließenden Versuchen verwendet. (Über die Gewinnung festsetzungsbereiter Larven vgl. Kap. VI.)

a) Das Bohren in Kalkstein und Molluskenschalen

Als Material, in das sich die Tiere einbohren sollten, wurden glatt gewaschene und stark angewitterte Kalksteine aus dem Geschiebe gewählt. Die Muschelschalen wurden zum Teil, um eine Beobachtung zu erleichtern, vorher angeschliffen. Außerdem wurden Muschelschalen angeboten, in die sich schon früher Polydoren eingebohrt hatten, dann waren aber schon vorher die Sandröhren restlos aus den Bohrlöchern entfernt. Die Versuchsanordnung wurde im èinzelnen vielfach abgewandelt. Nur folgende Versuche führten zu Ergebnissen:

Angewitterte Kalksteine aus dem Geschiebe befanden sich in einem Aquarienbecken auf einer mehrere Zentimeter dicken Schicht reinen Seesandes. Auf oder neben die Steine, die mit einer dünnen Feinsandschicht bedeckt waren, wurden mehrere bewohnte Polydora-Röhren aus den oben beschriebenen Zuchten gelegt. Der Sand wurde von den Würmern zur Verlängerung der Röhren

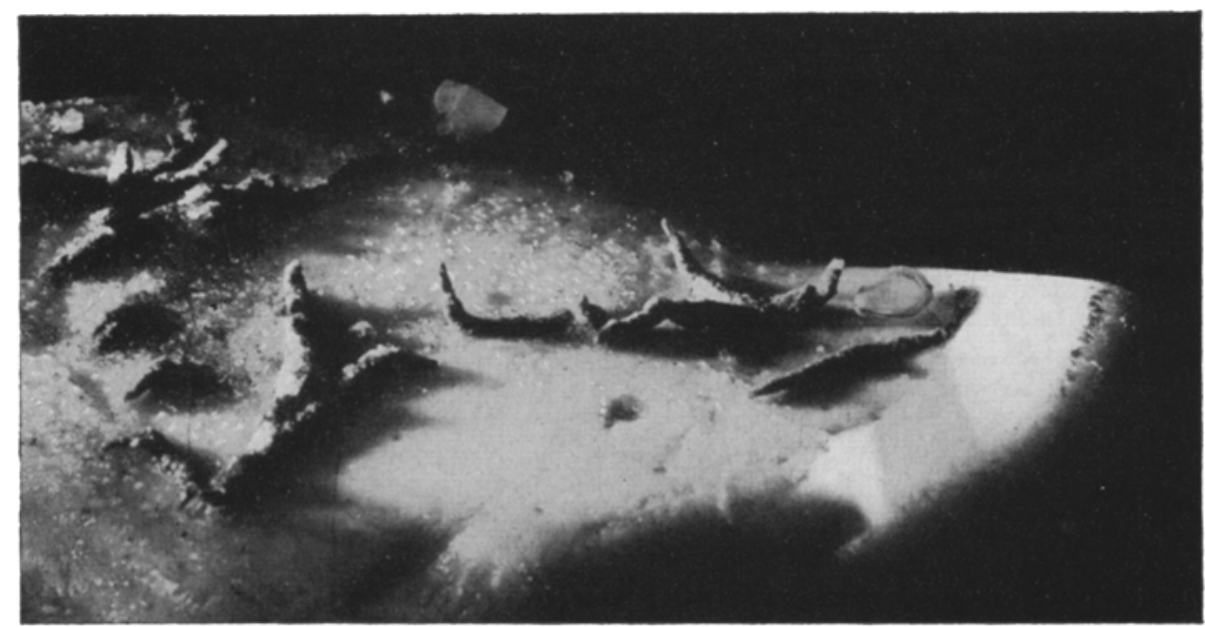

Abb. 11. Polydora ciliata. An der Oberfläche eines Kalksteines sind mit Gespinnstfäden Sandröhren befestigt, auf die kleine Schornsteine aufgesetzt sind. Die Röhren wurden im Aquarium gebaut

benutzt. Nach einigen Tagen war der neugebaute Röhrenabschnitt mit Gespinstfäden an dem Stein befestigt, und zwei Wochen später lag auf dem Stein ein neues Röhrensystem: eine waagerechte fest angesponnene Röhre, auf die mehrere kleine Schornsteine senkrecht aufgesetzt waren (Abb, 11). Nach mehr als zwei Monaten konnte ich an einem Ende der Röhre die erste kleine Vertiefung im Kalkstein beobachten. Wieder zwei Monate später war diese $3 \mathrm{~mm}$ tief und die Röhre in die kleine Höhlung hinein verlängert. Nach insgesamt fünf Monaten stand die Röhre an der Oberfläche des Steines mit der im Bohrloch eingebetteten gar nicht mehr in Verbindung. Der Wurm bewohnte die Röhre im Stein. 
Angeschliffene Molluskenschalen und glattgewaschene Kalksteine nehmen die Tiere gar nicht an. Bei den schon früher angebohrten Molluskenschalen drangen die Würmer oder einige Larven aus dem Auswaschrückstand in die alten Höhlungen ein. Waren die Schalen teilweise übersandet, wurden Röhren von mehreren Millimetern Länge gebaut. Die Tiere starben sehr bald.

Wegen der Länge der Zeit, die zur Herstellung eines Bohrloches im Aquarium benötigt wird, ist eine direkte Beobachtung, ob zur Bohrarbeit die Borsten des fünften Segmentes benutzt werden, unmöglich. - Die Herstellung der Bohrlöcher geht im Freiland wesentlich schneller. Vielleicht veranlaßt starke Wasserbewegung den Wurm zu rascherer Bohrarbeit. Zumindestens scheint ein Zusammenhang zwischen Brandung und Bohrtätigkeit zu bestehen.

b) Das Bohren in Ton

Da es anzunehmen war, daß die Würmer sich in ein weniger widerstandsfähiges Material schneller einbohren würden, bot ich den Tieren in anderen Versuchen anstelle von Kalkstein Ton an. Die Versuchsanordnung war die gleiche wie bei $P$. ligni und $P$. redeki. Nach ungefähr einer Stunde hatten sich die Würmer in den Ton eingegraben, wobei die Borsten in der gleichen Weise gebraucht wurden, wie es für die beiden immer in Ton siedelnden Arten beschrieben wurde. Die Schleimabsonderung von P. ciliata war bei dieser Bohrtätigkeit besonders stark. Nach einer mehrstündigen, von einigen längeren Ruhepausen unterbrochenen Arbeit, war eine mehrere Millimeter tiefe Höhlung in die Tonmasse eingegraben. Beim Bohren in Ton kommt nur eine mechanische Bohrweise in Frage.

\section{Beobachtungen an den von Polydora ciliata hergestellten Bohrlöchern}

Die Form eines fertigen Bohrloches im Kalkstein wurde bereits beschrieben. In Abb. 12a-e stellte ich eine Serie von unvollständigen Bohrungen in einer Austernschale zusammen. Die gezeigten Stadien kommen sehr häufig vor und sind in anderen Molluskenschalen ähnlich gestaltet.

Ich rekonstruierte in folgender Weise danach die Bohrtätigkeit: In Abb. 12a sind die ersten Bohrspuren zu beobachten. Der Wurm hat kriechend (genau wie beim Bohren im Ton) mit den Borsten eine nierenförmige Vertie-fung in die Muschelschale geraspelt, die durch spätere Abtragung an einer Seite eine Schrägung bildet, die tiefer in die Schale hineinführt. Durch Abpräparation der oberen bebohrten Schichten wird der weitere Verlauf des Bohrganges sichtbar (Abb. 12b-d). Wir erhalten eine schräge, bogenförmige Vertiefung, bei welcher in der Mitte zwischen zwei Stellen stärksten Bohrens ein Hügel stehenbleibt. Der Wurm trägt nur an der Innenseite ab.

Aufgespaltene Austernschalen zeigen in ihren Lamellen oft schlingenförmige, waagerecht verlaufende Vertiefungen, in die der Wurm seine Röhren einbettet. Solche Spuren kommen in weicherem Material ebenfalls durch das bogenförmige Kriechen zustande. Diese Gänge brauchen nicht schräg in die Tiefe zu führen, da sie zwischen den schützenden Lamellen der Muschelschale liegen. Eine Wand aus Sand und Detritus trennt die Höhlung in zwei gleiche Hälften (Abb. 12e). Im Inneren der Schale erhält man, nach Abtragen einiger Kalklamellen, ein in Aufsicht nierenförmiges Bohrloch. Das Vorhandensein 
von feinsten Raspel- und Kratzspuren läßt darauf schließen, daß mechanische Arbeit vorliegt. Diese Spuren liegen am häufigsten an der Bogeninnenseite und manchmal zwischen den feinen Schichten der Lamellen. Sie sind nur selten in dem übrigen Gang zu erkennen, was man leicht so erklären kann: Die Polydora verwischt selbst wieder ihre eigenen Spuren, wenn sie häufig darüber hinkriecht.

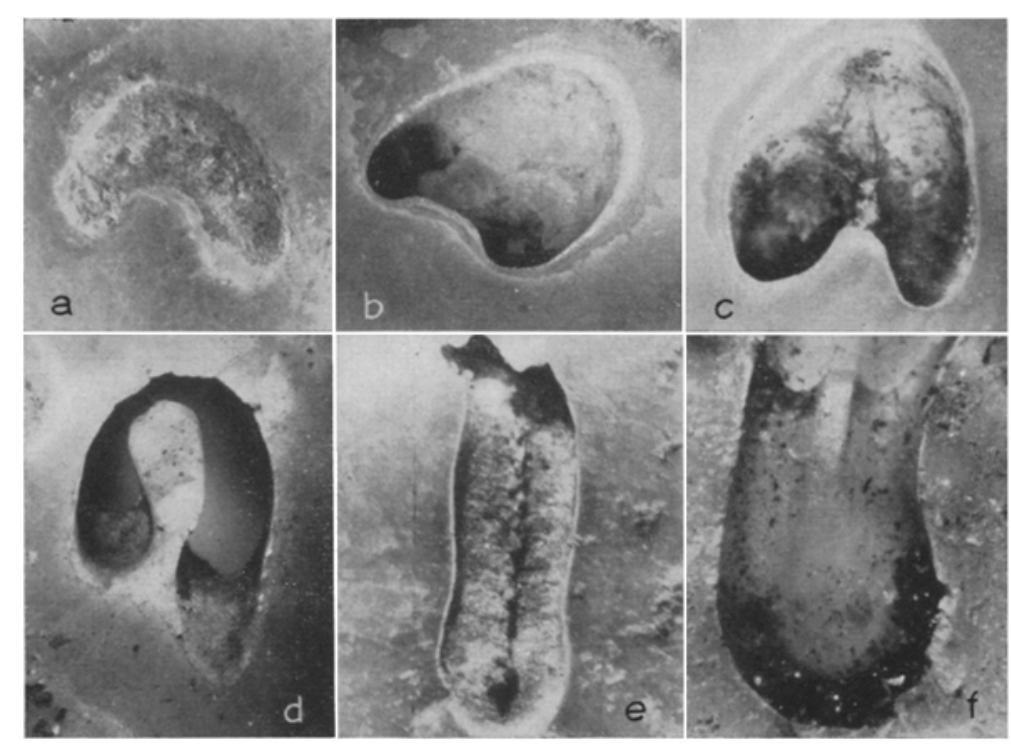

Abb. 12. Polydora ciliata. a) Erste Spuren der Bahrtätigkeit. Der Wurm raspelt kriechend eine nierenförmige Vertiefung in die Muschelschale. b) An der konkaven Seite wird am stärksten abgetragen, so daß eine Schrägung entsteht. c) Eine aus Sandkörnchen aufgebaute Wand schafft zwei Eingänge in die Höhle. d) Bogenförmige Vertiefung. In der Mitte zwischen zweì Stellen stärkster Abtragung bleibt ein "Hügel" stehen. e) Schleifenförmige Bohrspur. In der Mitte eine dünne Wand aus Sandkörnern. f) Schleifenförmige Bohrspur. In der Mitte anstehend der "Zentralhügel".

Die Gänge sind in Muschelschalen häufig unregelmäßig gestaltet infolge des verschiedenen Widerstandes, den die einzelnen Schalenschichten dem Wurm entgegensetzen. Je härter das Material ist, desto enger müssen die Schlingen angelegt werden. Im Kalkstein fand ich an der Oberlläche meist nu: die Hantelform. Der Wurm gräbt sich in diesem Fall sehr steil ins Substrat ein.

Aus der Ähnlichkeit der Röhren und Bohrformen in Muschelschalen, Kalkstein und Ton kann man auf eine gleiche Bohrweise in Kalk und Ton schließen. Im Ton stellten die Würmer die Höhlungen mit Hilfe der Borsten des fünften Segmentes rein mechanisch her.

\section{Das Werkzeug}

Nehmen wir eine mechanische Bearbeitung des Kalkes mit den Borsten des fünften Segmentes an, so ist es naheliegend, an diesem Werkzeug nach Spuren einer Abnutzung zu suchen, die durch die Bohrtätigkeit hervorgerufen wurde. 
Eine Abnutzung ist tatsächlich deutlich zu erkennen.

Aus Tieren, die in Kalkmaterial gebohrt hatten, wurden die Borsten des fünften Segmentes herauspräpariert.

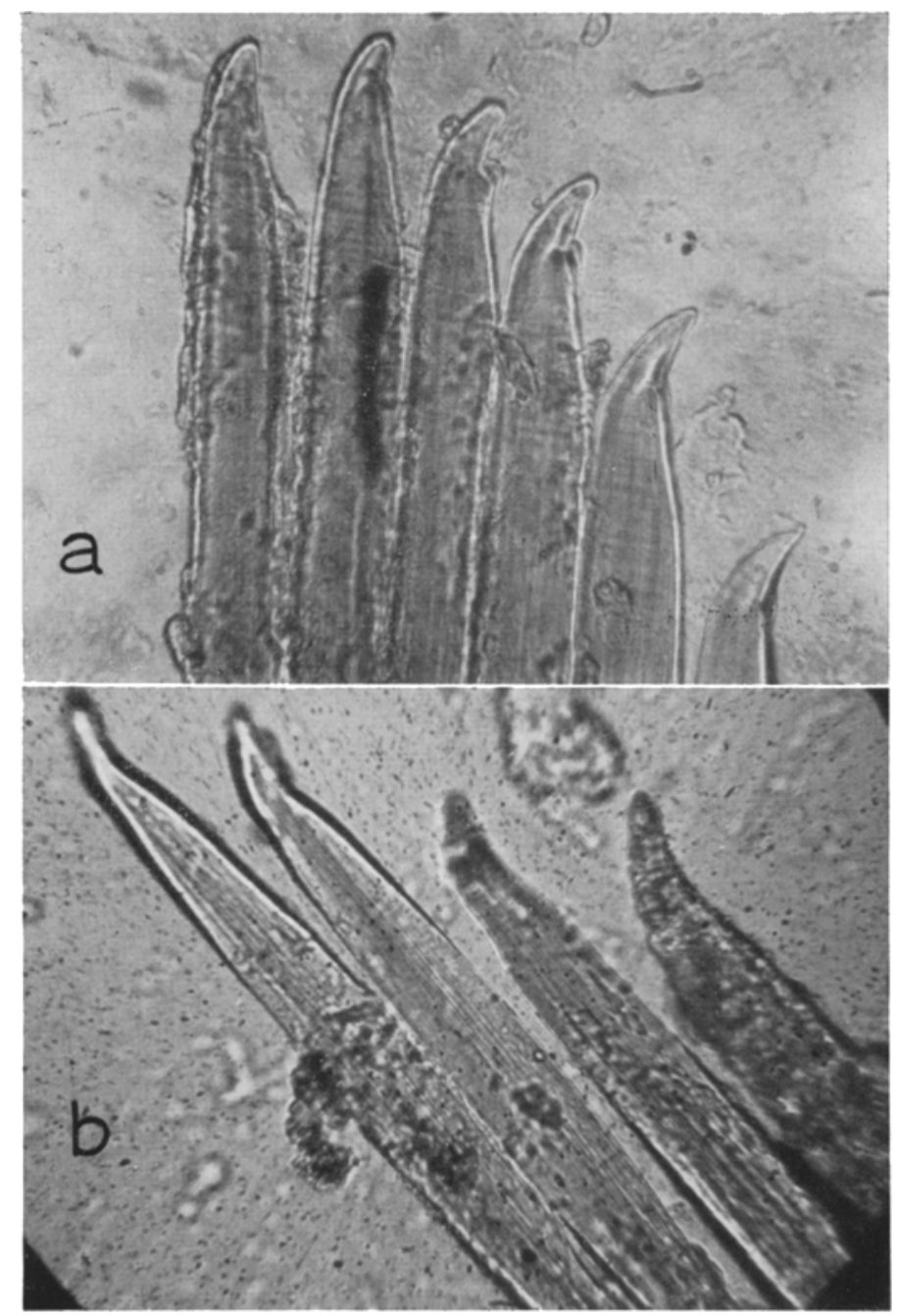

Abb. 13. Die Messerborsten des fünften Segmentes von Polydora ciliata. a) Aus einem Wurm herauspräpariert, der vorher in einer Muschel gebohrt hatte. Die vorderen Borsten sind deutlich abgenutzt. b) Borsten eines Wurmes, der nicht gebohrt, sondern in Sand gebaut hatte. Die ersten Borsten enden spitz und sind länger als die folgenden.

Abb. 13a-b zeigen die Borsten des fünften Segmentes einer Polydora, die nur in Sand gebaut hatte, und einer anderen, die aus einer LittorinaSchale stammt. Während bei den Tieren aus dem lockeren Sediment die vorderen Borsten spitz oder fast spitz endigen und der Größe nach abgestuft sind, sind die ersten drei Borsten der Tiere, die ein Bohrloch hergestellt hatten, stumpf, und der kleine seitliche Zahn ist häufig nur noch im Ansatz oder gar nicht mehr zu erkennen. Bei den bohrenden Tieren fehlt eine Längenabstufung gegenüber den folgenden Borsten. 
Nicht bei allen Würmern, die in Kalk gebaut hatten, zeigen die vorderen Borsten eine solche Abnutzung, was damit zu erklären ist, daß einige Würmer sicher in schon bestehende Höhlungen eindringen und dort hinein ihre Röhren bauen. Sie benötigen dann ihre Borsten kaum oder gar nicht zur Herstellung eines Bohrloches.

Eine entsprechende Abnutzung des Werkzeuges wies ZiEgelmeier (1954) für Lunatia nitida nach. Diese Raubschnede bohrt mit Hilfe ihrer Radula die Schalen verschiedener Muscheln an und frißt das Wirtstier durch das Bohrloch aus. Nach der Herstellung eines Bohrloches sind die Mittel-, Seiten- und Randzähne der Radula abgestumpft.

\section{Erweiterung der Polydora-Röhren beim Wachstum der Tiere}

Ein wesentliches Problem ist, wie die Tiere ihre Röhren beim Wachstum vergrößern. Jüngere Würmer, d. h. solche mit geringerer Segmentzahl, bewohnen kleinere Röhrensysteme als ältere Tiere.

Anscheinend haben die Polydoren bei der Erweiterung ihrer Röhren mehrere Bauprinzipien; diese stimmen mit der Vergrößerung der Bohrlöcher in Kalksubstanzen überein.

1. Röhre und Bohrloch werden nach unten hinverlängert. In der Krümmung des U ist die Sandröhre nicht stabil oder sie fehlt ganz. In schmalen Küvetten konnte für $P$. quadrilobata beobachtet werden, daß die Wohnung an der instabilen Stelle später nach unten erweitert wurde. In gebohrten Höhlungen sind deutlich bogenförmige Bohrlinien und feine Bohrspuren zu erkennen (s. S. 118-119), die von verschiedenen Arbeitsgängen zeugen und auf eine Tieferverlegung des Röhrensystems schließen lassen (vgl. PReLL).

2. In dem relativ weichen Material z. B. einer Austernschale können entsprechend dem W- und UU-Typ der Röhre neue Gänge seitlich angeschlossen werden.

3. Nur selten scheint der Wurm seine alte Wohnung zu verlassen. um sich seiner Größe entsprechend eine neue Röhre zu bauen.

\section{Die Auswahl des Baumaterials}

Im Aquarium wurden in Auswahlversuchen für $P$. ciliata die Partikelgrößen bestimmt, die zum Bau verwendet werden, und beobachtet, ob die Würmer aus dem Angebot irgendein Material bevorzugen.

Beim Röhrenbau verwendete Korngrößen:

$1 \mathrm{~mm}$ wird nicht bewegt

$1-0,5$ "wird bewegt

0,5 , wird bewegt, auch von einem Tentakel allein oder mit dem Prostomium, aber nicht eingebaut

0,3 "wird selten in der Tentakelrinne befördert und eingebaut

0,2 " wird in der Tentakelrinne befördert und eingebaut

$0,1-0,5 \mathrm{~mm}$ bevorzugte Partikelgröße beim Bauen in Sand

Für die Auswahl des Baumaterials ist weniger die Korngröße als seine Oberflächenbeschaffenheit und das Gewicht der einzelnen Partikel bestimmend. Von zermahlenen Ziegelsteinen oder Kohlesplittern wurden wesentlich größere Partikel mit den Tentakeln eingebracht als von rundgewaschenen Quarzkörnern. Die Ziegelsteine sind leichter als der Sand und haben außerdem eine rauhe Oberfläche, an der die Cilien bessere Ansatzpunkte finden. 
Leichte Nahrungspartikel, die herangeschafft werden, können oft die vielfache Größe der Röhrenöffnung haben.

Das von $P$. quadrilobata bevorzugte Baumaterial ist etwas feiner. Aus fertigen, im Königshafenwatt von List gebauten $P$. quadrilobata-Röhren wurden unter dem Binokular mit dem Objektmikrometer die Partikel vermessen, die das Tier in die Röhre eingebaut hatte; ausgeschlossen wurden diejenigen. die möglicherweise aus dem umgebenden Substrat an der Röhre angeheftet waren. .

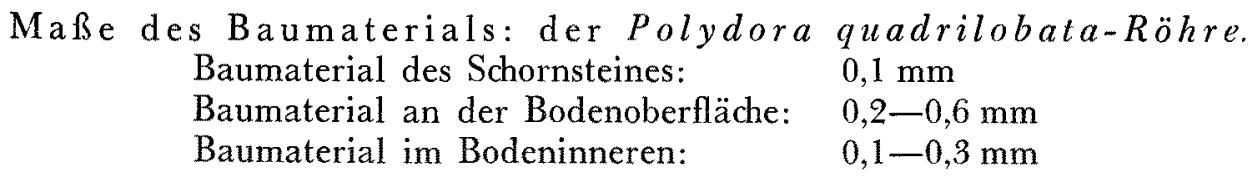

\section{Die Pygospio-Wohnröhre}

Pygospio elegans ist im untersuchten Gebiet in Sand- und Weichböden des Eu- und Sublitoral weit verbreitet. Diese Spionide tritt oft in sehr dichten Siedlungen auf. Am Rande von Schlicksandschollen z. B. stehen die Röhren zu Tausenden dicht beieinander, und in festem Sand bilden sie stellenweise einen Röhrenrasen. An Steinen oder Molluskenschalen angesponnen, sind sie auch in der Brandungszone zu finden.

Das Bauschema von Pygospio weicht von dem der Polydora-Arten ab. Die Wohnröhre ist nicht U-förmig, sondern gerade ${ }^{7}$ ). Im oberen Drittel der Röhre führen eine (vgl. Thamdrup 1935) oder auch mehrere Abzweigungen in verschiedenen Winkeln zur Bodenoberfläche und im mittleren und unteren Teil kurze Abzweigungen nach unten. An unverletzten Spitzen von PygospioRöhren fand ich fast immer ein aus erhärteten Schleimfäden gesponnenes Filternetz.

Länge der Röhre: 8-10 mm. Durchmesser der Röhre: 0,75-1 mm.

Um die Bauweise der Röhre und des Filternetzes beobachten zu können, wurden in der in Kap. IV, 3 beschriebenen Weise Kulturen angelegt und einzelne Tiere beim Bau unter dem Binokular beobachtet. Pygospio beginnt ihren Röhrenbau so, wie es für Polydora quadrilobata beschrieben wurde, in dem sie sich aus einer provisorischen Schleimhülle, die sie an der Bodenoberfläche schützt, in das Sandlückensystem hineinzwängt.

Diese schnell ausgeschiedene Schleimhülle zeigt keinerlei Struktur. Die Röhre, die der Wurm dann im Boden baut, besteht aus wenigen Schichten sehr gleichmäßig aneinandergefügter, größerer Sandkörner, die von Schleim zusammengekittet werden. In den Lücken dazwischen liegen feinere Partikel und Bruchstücke von Muscheln oder Seeigelstacheln. Außerdem ist Eisenhydroxyd eingelagert. Den inneren Abschluß bildet auch hier eine sehr dünne Schleimtapete. Häufig werden die Teilchen von den Borsten und Parapodien unter peristaltischen Bewegungen hin- und hergeschoben, bis sie gleichmäßig nebeneinander liegen. Einige werden von der Mundöffnung mit in die Röhre genommen und dort von innen eingefügt. Dies wurde wieder mit gefärbtem Sand nachgewiesen (vgl. Kap. III, 1). Der Bau wird zunächst von oben nach unten angelegt, dann aber unter häufigem Umdrehen des Wurmes innerhalb der Wohnung von unten nach oben vervollständigt. Das Baumaterial richtet sich nach der Sedimentzusammensetzung. In Weichböden werden die Röhren

7) Eine gute Beschreibung von Siedlungsweise und Röhre von Pygospio gibt Linke nach Beobachtungen im Jadebusen. 
aus Schlammpartikeln und Pflanzenteilen, in Schillansammlungen aus Bruchschill gebaut. Aus einem Gemisch, das den Würmern in Versuchen angeboten wurde, bevorzugten sie die gröberen Teilchen. - Die von Pygospio im Aquarium ohne Störung angelegten Röhren sind unverzweigt. Durch künstliche Wasserbewegung erzeugte Risse in der Wand werden als neue Offnung verwendet, durch die das Tier sich mit den Tentakeln und dem Prostomium herausschiebt und an der weitergebaut wird. Der alte vordere Abschnitt erscheint

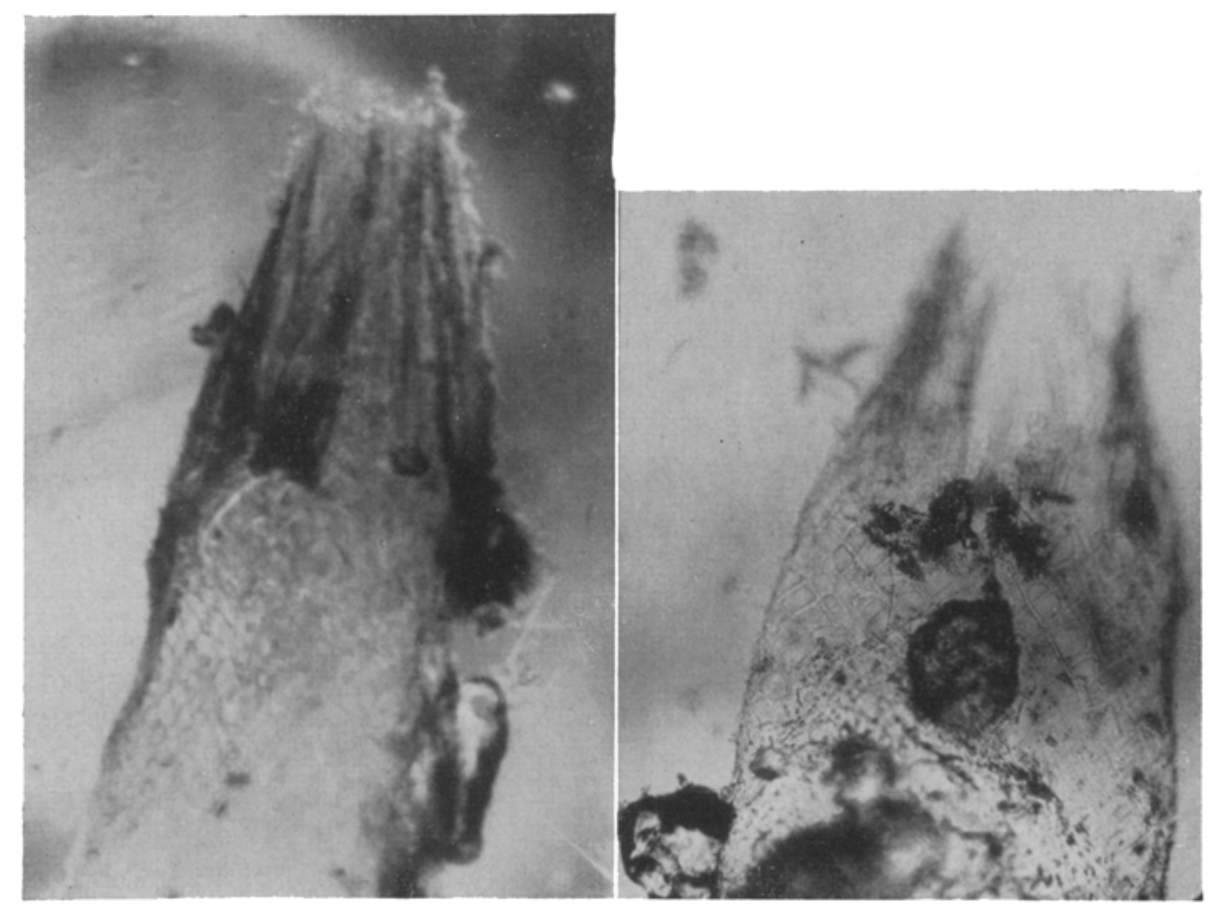

Abb. 14. Pygospio elegans. a) Filternetz an der Spitze der Wohnröhre. b) Wabenstruktur

dann als "Abzweigung", ist innen bald verklebt und wird nicht mehr benutzt. - Von oben nach unten nimmt auch bei der Pygospio-Röhre die Festig.keit ab und besteht in ihrem letzten Drittel aus einem Schleimmantel, an dem Sandkörner des umgebenden Sedimentes festhaften. Über die Bodenoberfläche ragende Schornsteine fehlen.

Bisher unbekannt war der Bau des Filternetzes, welches im Freiland an der Röhrenspitze gesponnen wird (Abb. 14). In den obersten $1^{1 / 2}-2 \mathrm{~mm}$ ändert sich die Struktur der Schleimhülle. Zunächst İöst sich die homogene Sekrettapete in sehr gleichmäßige Waben auf, die mit Bausteinen besetzt sind. Nach 10-15 Wabenreihen laufen 2-2,5 $\mathrm{mm}$ lange, dicht nebeneinander stehende Streben aus erhärtetem Schleim nach oben zusammen. Viele einzelne Sekretfäden sind untereinander verklebt und in drei Gruppen "wie die Seiten einer Pyramide" (Hannerz) angeordnet. Sie werden vom Wurm auseinandergeklappt, wenn er mit dem Kopfabschnitt aus der Röhre heraustritt. In mehreren Fällen fand ich auch die kleinen Pyramidendreiecke mit Sand beklebt. Im Aquarium (ohne Wasserzirkulation) beobachtete ich nur zwei Röhren mit Filternetz und konnte die Tiere bisher auch nicht bei der Herstellung der 
Netze beobachten. Im Freiland werden sie offenbar sehr schnell nach Röhrenverletzungen neu gesponnen. Denn selbst in Biotopen, welche zerstörender Wasserumlagerung ausgesetzt sind, besitzen fast alle im Sediment gebauten Röhren ein Filternetz. Dieses verhindert, daß Fremdkörper in die Wohnung hineinfallen, kleine Teilchen vom Atemwasserstrom mitgerissen werden oder Feinde eindringen können. HanNerz fand ebenfalls diese Schutzeinrichtung an der Röhrenspitze und nimmt an, daß sie das Findringen von Feinden, besonders von jungen $\mathcal{N} e$ phthys hombergi verhindern soll ${ }^{8}$ ). Bei den PolydoraArten werden Fremdkörper zum zweiten Schornstein wieder herausgespült. Bei Pygospio ist eine Röhrensäuberung auf solche Weise nicht möglich. Das Filternetz steht offenbar außerdem im Dienste des Nahrungserwerbs.

In der Brandungszone baut Pygospio nicht im Sediment, sondern auf Steinen oder leeren Muschelschalen. In der Brandungszone am Amrumer Kniepsand fand ich mehrere Exemplare von Petricola pholadiformis mit je 10-20 bewohnten Pygospio-Röhren, und am Nordstrand des Lister Ellenbogen solche Röhren in den Häusern von Crepidula.

Die Röhren sind an den Steinen und an den Molluskenschalen mit Gespinstfäden sehr fest verankert. Sie sind immer verhältnismäßig kurz und meistens mehrfach verzweigt. Die Pygospio-Röhren an Steinen unterscheiden sich von den in Abb. 8 gezeigten Polydora ciliata-Röhren schon äußerlich durch das Fehlen der kleinen Schornsteine.

\section{Brutpflege und Festsetzen der Larven}

Die Darstellung des Röhrenbaus in den vorhergehenden Kapiteln gründet sich auf Untersuchungen an erwachsenen Spioniden. Uber das Verhalten der Jugendstadien und den Bau der ersten Röhre ist bisher nur sehr wenig bekannt.

Eine umfassende Beschreibung der Larvalentwicklung der Spioniden und eine Zusammenstellung der früheren Literatur, aus der die Arbeiten von SöDERSTröm (1920) und die von WILson (1928) (Polydora hoplura und Polydora armata) besonders zu erwähnen sind," gibt HANNERz.

Im folgenden werden einige Beobachtungen zur Larvalentwicklung im Untersuchungsgebiet und über das Verhalten der Jugendstadien beim Festsetzen wiedergegeben.

\section{Die Brutröhre}

Zahlreiche Spioniden-Arten betreiben, wie in der Literatur beschrieben wird, Brutpflege. Sie legen ihre Eier in Säckchen ab, die an der Röhrenwand befestigt sind und aus einer von den Drüsen der mittleren Körpersegmente ausgeschiedenen Haut bestehen. (Ausführliche Beschreibung bei Söderströм 1920.) Die Wohnung der Spioniden wird zur Zeit der Eiablage als Brutröhre bezeichnet.

Bei einigen Arten unterscheiden sich die Wandungen der Wohn- und Brutröhren voneinander. Durch starke Schleimabsonderung verstärkt der Wurm die innere Tapete und erhöht dadurch die Festigkeit des Röhren-

8) Watson (1907) beschreibt für Sabella spec., daß die obere Röhrenspitze meist zusammengeklappt ist, um den Wurm vor Feinden zu schützen. Eine felsbohrende Sabellide rollt nach ds. Autor (WATson 1891) die Röhrenspitze wie ein Farnblatt ein. 


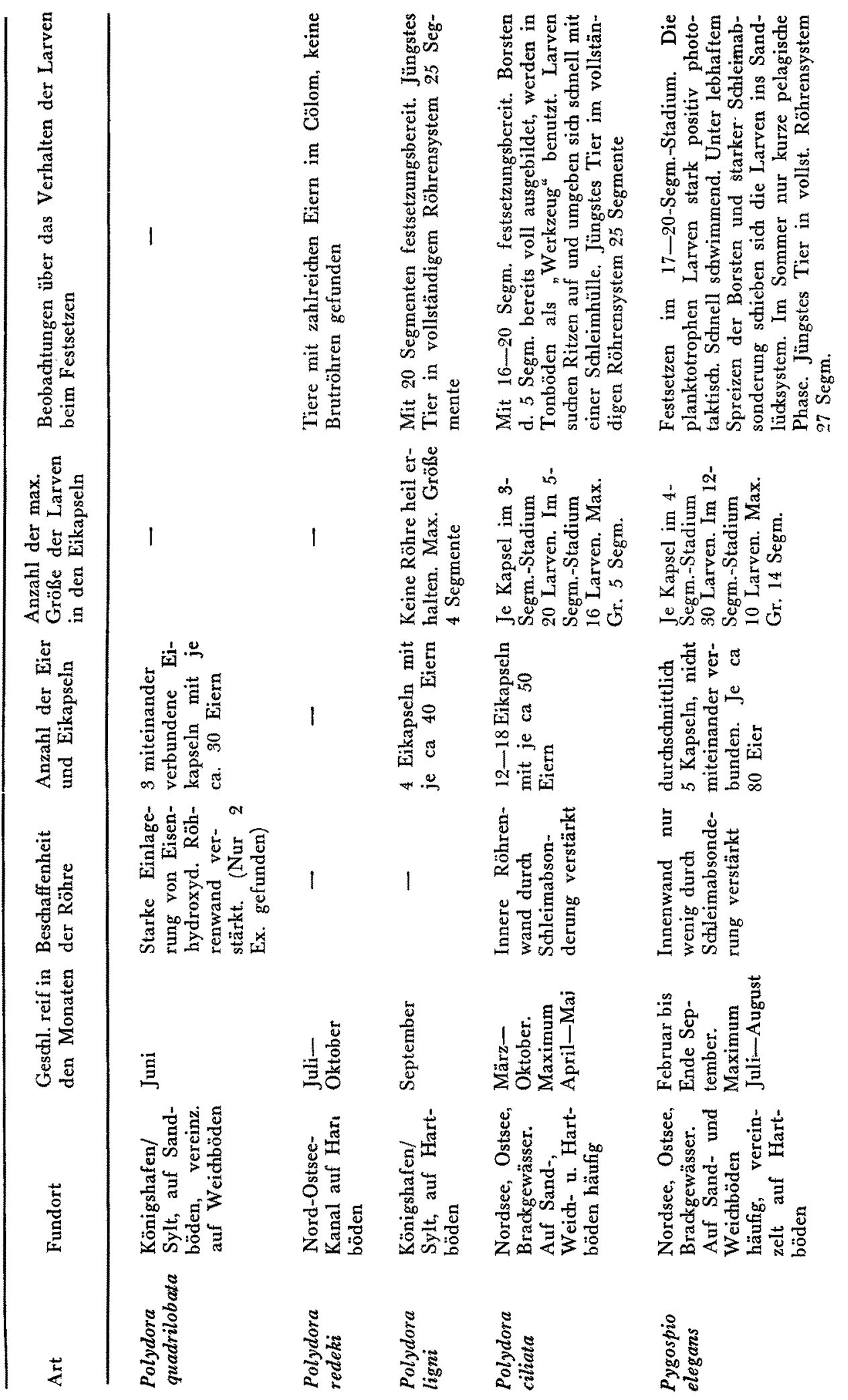


systems. Auch der untere sonst instabile Abschnitt der Röhre ist während der Brutpflegezeit fester gebaut.

Bei Polydora redeki und quadrilobata wird außerdem sehr reichlich Fisenhydroxyd in die Röhrenwand eingelagert. Nach der Eiablage bleibt das Muttertier in der Röhre. Der Atemwasserstrom umspült die Eier. Die jungen Larven ernähren sich zunächst vom Dotter, unbefruchteten Eiern und schwächeren Embryonen (Hannerz). Bei Polydora ciliata konnte ich Larven von 4 Segmenten bei der Aufnahme von kleinen Partikeln aus dem Atemwasserstrom des Muttertieres beobachten. Tab. 1 faßt die Beobachtungen der ersten Larvalentwicklung zusammen.

\section{Verhalten der Larven beim Festsetzen}

Die Larven, die zum planktonischen Leben übergehen, schwimmen nach Verlassen der Brutröhre unter heftigem Spreizen der Borsten sofort in Wasserschichten, die unter Lichteinfall stehen. Nach einer unterschiedlich langen planktonischen Phase (einige Stunden bis Tage) kehren die Larven zum Festsetzen an den Boden zurück.

Um solche Larven zu erhalten, wurden im Sommer Muschelschalen, die von Polydora ciliata befallen waren, vorsichtig mit Seewasser abgewaschen. Dabei erhält man zwei verschiedene Stadien. Eins mit 4-5 Segmenten und ein viel größeres mit 18 Segmenten. Bei den jüngeren Tieren handelt es sich um Larven, die gerade die Brutröhre verlassen, während die älteren, bei denen die Borsten des fünften Segmentes bereits vollständig entwickelt sind, im Begriff sind, zum Bodenleben zurückzukehren.

Im Gegensatz zu den Larven, die man aus Planktonfängen erhält, sind diese nicht mehr positiv phototaktisch. Den Tieren wurde eine Austernschale angeboten, die etwas beschliffen war, um größere Unebenheiten und Unterschlupfe zu vermeiden. Die Larven schwammen unter Spreizen der Borsten dicht über der Muscheloberfläche, krochen darauf ein Stück entlang und schwammen unter Abstemmen mit den Borsten wieder auf. Dies wiederholte sich mehrere Male, bis eine kleine Vertiefung, ein Spalt oder eine sonstige Unebenheit gefunden war (Kap. III, 3). Dort heftete sich die Larve unter sofortiger Schleimabsonderung, die mit peristaltischen Bewegungen verbunden ist, fest. Nach kurzer Zeit wurden die Messerborsten in gleicher Weise bewegt, wie oben für die Bohrtätigkeit der adulten Tiere beschrieben ist. Metamorphose-reife Larven, denen ich Tonsubstrat anbot, gruben sich darin in kurzer Zeit eine kleine Vertiefung. Im Aquarium gelang es jedoch bisher nicht, die ganze Bohr- und Bautätigkeit eines Jungtieres zu beobachten. Die jüngsten $P$. ciliata, die in Muschelschalen gefunden wurden und in ein Bohrloch eingebettet ein vollständiges Röhrensystem mit zwei kleinen Schornsteinen besaßen, hatten 25 Segmente. - Ich fand nie mehr als 2 Jungtiere dicht beieinander siedelnd. Die Larven suchen vielmehr die Nähe der Röhren erwachsener Tiere auf und bilden unter sich keine Kolonien, wie es etwa bei den Balaniden der Fall ist.

Die jüngste $P$. ligni, die eine vollständige Röhre gebaut hatte, war im 6-Segment-Stadium.

HANNERZ beschreibt das Verhalten von $P$. ciliata-Larven in ähnlicher Weise und beobachtete, daß sie sich mit Hilfe eines Schleimes am Substrat anheften. Er vermutet für die Larven teilweise chemische Bohrweise (s. S. 104). Fast regelmäßig auftretende, feine Kratzspuren in unvollständigen Bohrungen 
und die Tatsache, daß auch Jungtiere sich mit den Borsten des fünften Segmentes in Tonböden einzugraben versuchen, sprechen zumindest für eine Be. teiligung der Borsten auch bei der Bohrarbeit der Larven.

Beim Auswaschen der oberflächlichen Schichten einer Pygospio-Siedlung erhielt ich auch von dieser Art einige Jungtiere, die noch keine Röhre gebaut hatten. - In den Versuchsschalen, in denen ich sie anschließend beobachtete, umgaben sie sich sofort mit einer Schleimhülle. Unter heftigen peristaltischen Bewegungen versuchten sie sich, oft in Seitenlage, dann zwischen die Sandkörner zu zwängen. Bei einem Tier erschienen schon nach sehr kurzer Zeit die T'entakeln wieder an der Bodenoberfläche und beförderten die ersten Detrituspartikel zur Mundöffnung.

Auch von Pygospio wurden sehr junge Würmer (27 Segmente) in Röhren gefunden, die sich von denen der erwachsenen Tiere nicht unterscheiden; jedoch fand ich an der Röhrenspitze kein Filternetz.

\section{Die Nahrungsaufnahme der Spioniden}

Über die Ernährungsbiologie der Polychäten ist nur sehr wenig bekannt. Den Nahrungserwerb und die Verdauung bei Terebelliden beschreibt Dales (1955) sehr ausführlich (dort auch Literaturübersicht). RAUSCHENPLAT (1901) bezcichnet nach scinen Untersuchungen in der Kicler Bucht Polydora ciliata als Detritusfresser. Hunt (1923) erwähnt als Nahrung der ., selective Feeders", zu denen er die Spioniden stellt - untersucht wurde Magelona papillicornis sandigen Detritus, Diatomeen. Cysten und Sporen von Algen, Tintinniden und die Larven verschiedener Crustaceen, Mollusken und Würmer.

WATSON (1890) und ZregelmeIer (1952) beobachteten im Zusammenhang mit dem Röhrenbau den Nahrungserwerb von Lanice conchileg $a$. Nach THorson (1946) nehmen Polychätenlarven hauptsächlich Phytoplankton als Nahrung auf. HARLEY beobachtete bei dem räuberischen Polychäten Nereis diversicolor die Herstellung eines im Dienste des Nahrungserwerbes stehenden Filternetzes. Für die Metatrochophora-Larven von Chaetopterus variopedatus beschreibt WERNER (1953) den Nahrungserwerb mit Hilfe eines Schleimfilters. Eine ökologische Verteilung der Ernährungstypen gibt Remaxe (1933 u. 1940).

Bei den Untersuchungen über den Röhrenbau der Spioniden konnte ich auch zahlreiche Beobachtungen zur Ernährungsbiologie sammeln. Die Spioniden gehören zu den hemisessilen Tieren (Remane 1940). Die Polydora-Arten werden zu den Strudlern und Pygospio elegans zu den Tastern gerechnet. In diatomeenreichen Sandgebieten frißt Pygospio vor allem Diatomeen.

Wie das Baumaterial, so wird auch die Nahrung mit den Tentakeln eingebracht. Bei den Polydora-Arten, deren U-Röhrensystem zwei Kamine besitzt, werden beide abwechselnd bei der Nahrungssuche benutzt. Die Tiere verlassen ihre Wohnröhren nur bei sehr ungünstigen Milieuverhältnissen und bauen sehr schnell an einer anderen Stelle eine neue Röhre.

\section{Nahrungserwerb der Polydora-Arten}

Die Polydora-Arten sammeln ihre Nahrung hauptsächlich aus dem freien Wasser. In dem Raum dicht über der Bodenoberfläche stehen ihnen aufgewirbelte Bodentrübe, kleine Algen, niedersinkender Detritus und Plankter zur Verfügung. Alle Teilchen, die in den Bereich der schnell hin und her wedelnden Tentakeln kommen, werden auf den Wimperbändern zum Prostomium befördert. Erst dort findet eine Auswahl statt. Ich konnte beobachten, daß von dem Angebot kleine Planktonorganismen sicher als Nahrung dienen. Außer 
dem oben (S. 102, 105) beschriebenen Strudelmechanismus, in den der starke, von den Kiemenblättchen erzeugte Atemwasserstrom mit einbezogen ist, helfen gerichtete Tentakelbewegungen mit beim Einfangen freischwimmender Larven und anderer Planktonorganismen. Verschiedentlich beobachtete ich die Polydoren beim Beutefang. Die aus der Röhre herausragenden Tentakeln schlagen wild im Wasser umher. Gelangt dabei z. B. ein Harpacticide in den Bereich dieser Fangorgane, muß der Krebs einen Augenblick in dem Wirbel verbleiben. Durch schnelle Zusammenarbeit beider Tentakel wird er, wenn er nichi allzu groß ist, auf folgende Weise zum Prostomium befördert:

In dem Moment, wo die Beute an einem Tentakel verhaftet ist, schlingt sich der andere Tentakel darüber, und unter Steilstellung und Verengung dieser Schlinge wandert das Beutetier rasch zum Mund. Die Fangweise ist in

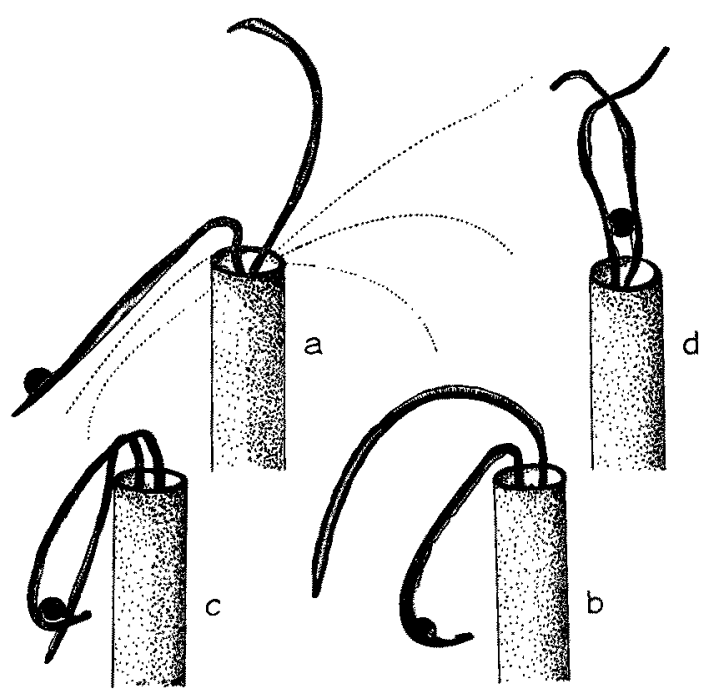

Abb. 15, a-d) Beutefang von Polydora ciliata

Abb. 15 dargestellt. Ein Harpacticide ist aber zu groß, um quer in die Röhre hinuntergezogen zu werden. Der kurze Pharynx des Wurmes wird vielfach ausgestülpt, wobei er den Krebs zu umfassen versucht. Wenn ein geeigneter Ansatzpunkt gefunden ist, wird die Beute unter Zerren hin und hergedreht, bis es gelingt, sie ganz oder ein Stück weit in die Röhre hinunterzunehmen. Unter dem Binokular beobachtete ich, daß nach einer halben Stunde die leere Chitinhülle des Krebses wieder aus der Röhre herausgeschoben wurde.

Im Aquarium fütterte ich die Zuchten manchmal mit frischen Planktonfängen. Mit einer Pipette konnte ich nach einigen Tagen die aus der Röhre herausgeworfenen Nahrungsreste einsammeln. Es waren vor allem Borsten junger Trochophoren und Harpacticiden-Hartteile. Auch in den Mägen einiger Polydora ciliata fand ich feine Haarborsten. Die Kulturen im Aquarium fütterte ich hauptsächlich mit „Piscidin“" und Enchytraen. Von „Piscidin" wurden die Körnungen 000 und 00 angenommen, d. h. sehr leichte Nahrungsteilchen, deren Durchmesser wesentlich größer ist als die maximale Bausteingröße. In Auswahlversuchen wurde die Größe der Planktonorganismen bestimmt, die von adulten Tieren als Nahrung aufgenommen wurden. Die größten Beutetiere waren $0,6 \mathrm{~mm}$ lang. In den Därmen der Polydoren befand sich außerdem 
von Algen gefärbter Sand. Im Aquarium bot ich den Würmern Sandkörnchen, die mit der kleinen Grünalge Protococcus bewachsen waren, als Nahrung an, die von $P$. ciliata vereinzelt gefressen wurde.

Im folgenden sollen kurz die Ernährungsbedingungen in den von $P$. ciliala besonders dicht besiedelten Biotopen beschrieben werden.

In sehr großer Wohndichte lebt $P$. riliata eingebohrt in Kalk- oder Kreidegestein mancher Steilküsten und in den Schalen der dort lebenden Mollusken. In den Felsritzen oder den vom Wurm geschaffenen Bohrlöchern sind die Röhren vom Wellenschlag geschützt, während die Tentakeln in der ernährungsmäßig besonders günstigen Brandungszone fischen können. Eine große Auswahl an Planktonorganismen, kleinen Tierleichen und Wassertrübe wird von jeder Welle gegen die Küste geworfen und bleibt teilweise zwischen den dicht beicinander stehenden Polydora-Schornsteinen hängen, die eine Art Sandfang bilden, Außerdem ist in dem extremen Lebensraum, den die Hartböden darstellen, die Zahl der Nahrungskonkurrenten sehr gering. Die gleichen günstigen Ernährungsbedingungen wie an den Steilküsten finden wir auch an manchen flach unter der Wasseroberfläche liegenden Steinbänken, so z. B. an dem von $P$, ciliat $a$ reich besiedelten Wittekliff am Nordende der Helgoländer Düne, über das ein starker Wasserstrom zieht, und an der Kante des Hauptprieles im Lister Königshafen-Watt. Dort fand ich das größte Vorkommen von $P$. ligni. Ein weiterer Biotop, in dem $P$, ciliata häufig ist, sind die Muschelbänke. - Für das Bestehen von Austernbänkén sind "ständige Wasserbewegung und damit immer neue Zufuhr von Plankton Voraussetzung (CAspers 1950). Die Helgoländer Austernbank z. B. ist am Nordhang eines Ausläufers der Helgoländer Tiefen Rinne gelegen, durch die der Wasserwechsel der Rinne teilweisê vor sich geht.. Ganz allgemein werden Prielhänge, die von einer Strömung getroffen werden, vơn Austern' bèvorzugt besiedelt (Hagmeter und Känderer 1927). Auch die Miesmuscheln bilden die größten Bänke in Wattabschnitten oder an Pfählen, die dem Gezeitenstrom stark ausgesetzt sind.:

Nicht allein die hydrographischen Verhältnisse schaffen für Polydora áuf Muschelbänken gute Ernährungsbedingungen. Auch die Gemeinschaft mit Tiéren desselben Ernährungstyps wirkt begünstigend. An den Tentakeln der Würmer streicht der von Mollusken erzeugte starke Wasserstrom vorbei, bevor ér in den Kiemenraum gelangt. Die Wassermenge z. B., die eine Miesmuschel in einem Tag filtriert, beträgt 45,5 Liter/Tag (Dogson, zit. bei LiNkE). Der Strudelmechanismus der Wirtstiere schafft dicht über der Bodenoberfläche kleine Turbulenzräume, die für den viel kleineren. strudelnden Polychäten den Beutefang erleichtern.

Abb. 16 zeigt den Befall von Balants mit P. ciliata, der schließlich zur Vernichtung der Balanidenkolonien führen kann. -

Die Polydoren siedeln bevorzugt an den Schalenrändern von Crepidula fornicata und den unteren Schalenrändern von Cardium. Littorina littorea, eine der meist befallenen Schnecken, ist vagil und sucht meist Lebensräume auf, die auch für Polydora optimale Bedingungen bieten, z. B. die Brandungszone, Muschelbänke und kleine Resttümpel im Watt. Viel weniger günstig sind die Lebensbedingungen für die Würmer auf toten Molluskenschalen, da diese bald übersandet werden.

\section{Nahrungserwerb von Pygospio elegans}

Pygospio elegans sammelt seine Nahrung fast ausschließlich an der Bodenoberfläche. Auch während der Niedrigwasserzeit sind in trockenfallenden Wattabschnitten die Tentakeln tätig, solange der Boden nur ein wenig feucht bleibt.

In der Sandregion ist er nach Remane (1933) der einzige Taster. Die langsam arbeitenden Tentakeln von Pygospio scheinen zum Fang von aktiv bewegter Beute nicht fähig zu sein. Nach HANNERz werden auch bei dieser Art Planktonorganismen mit den Tentakeln aufgenommen, was ich jedoch nie beobachten konnte. Getötete Plankter dagegen, die auf dem Boden in den Aktionsradius der Tentakel gelegt wurden, werden von den Tieren als Nahrung angenommen. Auch feingeriebene Enchytraen und „Piscidin“ wurden gefressen.

Wo Pygospio Weichböden besiedelt, stehen ihm Sinkstoffe als Nahrung zur Verfügung. Die wichtigste Nahrungsquelle für Besiedler der Sandböden 
sind Diatomeen. Einzelne Sandkörner werden eingebracht und „abgeleckt". In dichten Diatomeenbeständen kommt der Wurm mit seinem ganzen vorderen Körperabschnitt aus der Röhre heraus und weidet die Umgebung ab.

Das an der Spitze der Röhren gelegene Filternetz (s. S. 123), durch welches der Atemwasserstrom passieren muß, steht offenbar auch im Dienste des Nahrungserwerbs. Planktonorganismen, die an diesem Netz haften bleiben, werden, wie ich des öfteren beobachten konnte; vom Polychäten abgeweidet oder in die Röhre hinabgezogen.

LiNke gibt eine gute Beschreibung eines Wattgebietes mit reichem Vorkommen von Pygospio und Diatomeen.

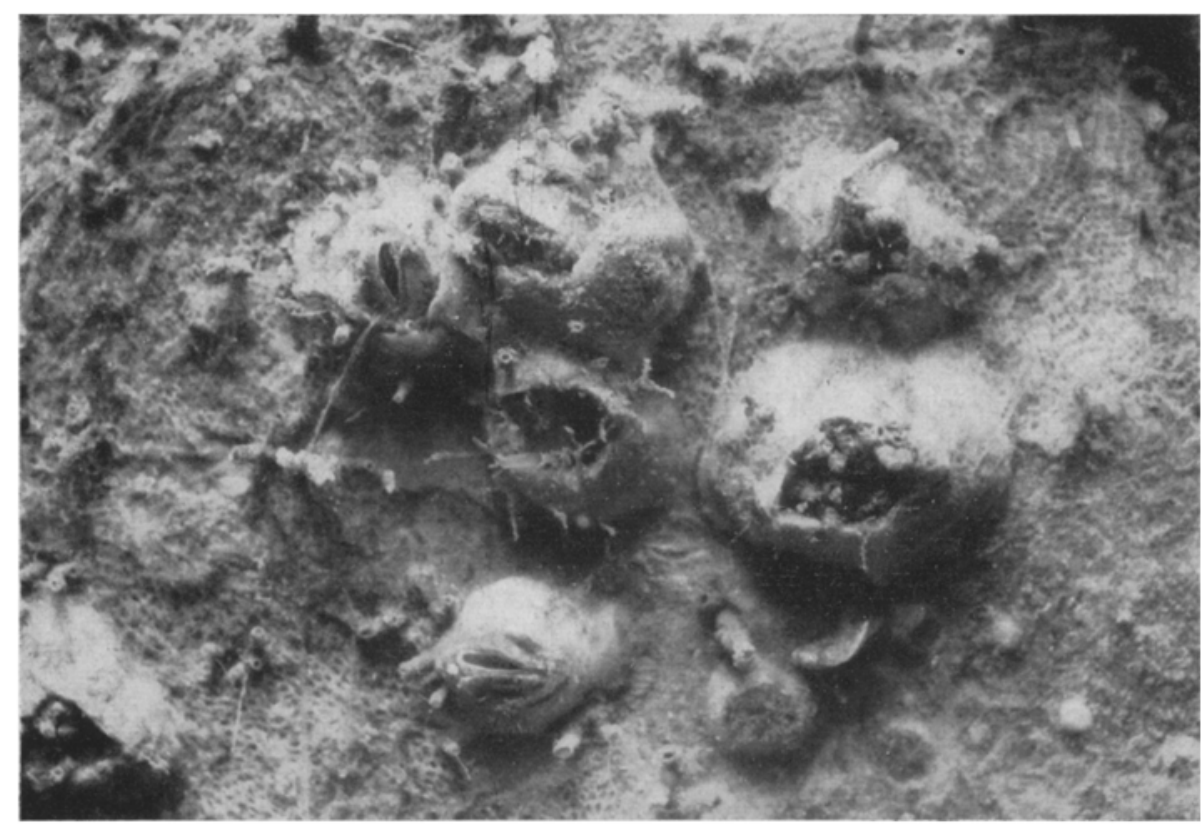

Abb. 16. Balaniden-Kolonie auf einer Schale von Ostrea edulis, die von Polydora ciliata befallen wurde. Ein Balamus ist völlig von Polydora-Schornsteinen ausgemauert. Die kleinen Kalkschilder stehen schützend um die Wurmröhren herum

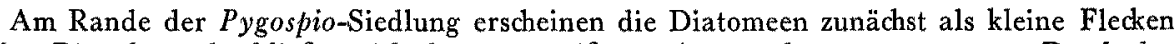
auf den Rippeln und schlicßen sich dann zu größeren Ansammlungen zusammen. Durch das ständige Hin- und Herwandern verschleimen die Diatomeenzellen die oberste Bodenschicht sehr stark. In dieser Schleimschicht bleibt Detritus haften, der wiederum die Diatomeenwucherungen begünstigt. So entstehen Schlicksandtafeln, auf denen $P$. elegans am häufigsten ist. Da die Diatomeendecke keine Festigkeit erreicht, ist sie für Pygospio kein Hindernis beim Bau der Wohnröhre. Die Röhren werden beim Anwachsen der Schlicksandschollen vom Wurm nach oben verlängert. Welche Diatomeenarten bevorzugt werden, konnte LiNKE nicht beobachten. Trotz der großen Wohndichte von Pygospio (stellenweise über $20000 / \mathrm{m}^{2}$ ) beeinträchtigen die Würmer die Entstehung einer Decke aus Kieselalgen nicht. Die Beobachtungen von LiNke stimmen gut mit den eigenen überein. Ich fand dichte Kleinsiedlungen von Pygospio an ein bis zwei Rippeln überdeckende Diatomeenflecken gebunden. An den Abbruchkanten der Schlicksandschollen kann man die Pygospio-Röhren dicht nebeneinander stehen sehen.

Die Sonderstellung, die Pygospio als Taster in Sandgebieten einnimmt, ist also damit zu erklären, daß der Wurm sich dort fast ausschließlich von Diatomeen ernährt. Diatomeenfresser sind für Sandgebiete typisch (REmane 1933). 
VIII. Zur geologischen Auswertbarkeit der Ergebnisse

Von geologischer Seite wurde der Bohr- und Grabtätigkeit der Spioniden des öfteren Interesse geschenkt. Hierfür gibt es drei Hauptgründe:

1. Für die Bestimmung fossiler Wurmspuren und die stratigraphische Einordnung ihrer Horizonte ist eine genaue Kenntnis der rezenten Bohrgänge und eine Unterscheidung zwischen bohrenden und grabenden Formen notwendig.

Auf zahlreichen Schichtflächen hauptsächlich aus der Trias sind fossile L.ebensspuren zu finden, deren Herkunft viel umstritten ist.

Sie wurden zunächst als Tetrapoden- oder Hühnerfährten beschrieben und später als Gänge sehr verschiedener Sandbewohner aufgefaßt. Prell (1925, dort auch Literaturübersicht) führt sie auf die Bohrtätigkeit von Polydora zurück und gibt den Schichten den Namen „Polydorinen-Horizont".

Hauptsächlich aus folgenden Schichten sind Spuren bekannt, die Polydora zugeschrieben werden:

Fährtenplatten des mittleren Buntsandstein bei Berka a. d. Ilm.

Buntsandstein der Rhön und Niederhessens.

Plattensandstein des württembergischen und badischen Schwarzwaldes.

Chirotheriensandstein des Taubertales.

Die Wurmspuren beschränken sich stets auf eine oder wenige Schichten in allen Gebieten ihres Vorkommens.

Nach PreLl ist bei den fossilen Gängen eine große Formenmannigfaltigkeit zu finden. Dies ist mit der Verschiedenartigkeit des Materials zu erklären, das den Würmern zur Bearbeitung zur Verfügung stand (vgl. rezente Gänge Kap. III, 4) und damit, daß nicht immer fertige, sondern auch unfertige Gänge vorliegen können (vgl. Abb. 12). Außerdem kann die Fossilisation auf verschiedene Weise erfolgt sein.

a) In widerstandsfähigem Gestein wurden die Röhren durch Ton ausgefüllt, wodurch typische U-Röhren erhalten bleiben.

b) War das Substrat, welches von den Würmern besiedelt wurde, locker, und wurden die Gänge durch haltbar petrifizierbaren Stoff ausgefüllt, so entstanden Steinkerne oder Ausgüsse der Röhren, die später herausgewittert als selbständige Fossilien erhalten sein können.

Für die Unterscheidung der Lebensspuren bohrender und grabender Formen gilt folgendes:

Bohrgänge wurden in bereits anstehendem, in früherer Zeit entstandenem Gestein angelegt und sind daher nicht als "Leitfossilien " zu bewerten. Das Gestein kann eine ältere marine Ablagerung oder in äolischer Zeit entstanden sein. Bei einer späteren Transgression wurde es von den Würmern besiedelt.

Bei den von PreLl beschriebenen Buntsandsteinplatten sind die Bohrgänge die einzigen Spuren organischen Lebens. Schalenreste von Muscheln oder Schnecken fehlen vollkommen, was darauf schließen läßt, daß es sich zur Zeit des Polydora-Befalles um Abrasionsflächen gehandelt hat, wie wir sie auf den Klippen und im Felswatt von Helgoland heute finden.

Einen Übergang von bohrender zu grabender Lebensweise finden wir auf einer Schichtfläche im Jurakalk, die DAGQUÉ beschreibt. Unter einer jurassischen Austernbank fand er im oberen Jura nordöstlich von Verdun Spuren 
einer Bohrmuschel und viel feinere von Bohrwürmern, die sich in der Jurazeit in den zähen und erhärteten Schlamm eingegraben hatten, - ähnliche Verhältnisse, wie wir sie auch heute bei den großen Muschelbänken finden.

Nach DACQué werden Wurmspuren hauptsächlich auf diskontinuierlich überlagerten Schichten gefunden, die vor ihrer Übersandung eine Zeitlang unbedeckt lagen und schon erhärtet waren. Choffat (zit. bei Dacqué) beschreibt eine Diskordanz zwischen Miozän und Jura, bei welcher die Jurafläche durch Polydora angebohrt war.

2. Zusammen mit anderen Bohrorganismen sind die Polydoren verantwortlich $z u$ machen für viele Bruchschillansammlungen und sind damit sedimentbildend - eine Bedeutung, auf die v. PIA im Zusammenhang mit der Bohrtätigkeit einiger Thallophyten hinweist (Lagunenkalk, vgl. auch WETZEL 1937).

3. In einer für niedere, hartteillose Tiereselten günstigen Weise sind Angaben über das erdgeschichtliche Alter der in Molluskenschalen bohrenden Würmer möglich. Eine genaue Untersuchung von fossilen Wurmspuren und Molluskenschalen läßt bei zahlreichen Conchylien auf Polydora-Befall schließen.

Bei prämortalem Befall haben die Würmer das gleiche erdgeschichtliche Alter wie die Mollusken.

Eine vergleichende Betrachtung erlaubt außerdem Schlüsse auf Lebensweise und Lebensbedingungen in den Meeren früherer Erdepochen.

\section{Zusammenfassung}

Die untersuchten Spionidenarten besiedeln sehr verschiedene Lebensräume, denen sie sich in ihrer Lebensweise, vor allem im Röhrenbau, angepaßt haben. Der Röhrenbau der Arten wurde untersucht und im Zusammenhang damit Beobachtungen über den Nahrungserwerb und die Brutpflege gesammelt.

Einzelbeobachtungen im Freiland und Versuche im Aquarium ergaben folgendes:

1. Die Wohnröhren der Polydora-Arten sind U-förmig. Über die Bodenoberfläche ragen zwei im Dienste des Nahrungserwerbs stehende Schornsteine. Diese werden vom Wurm aus mit Schleim vermischten Sand- oder Detrituspartikeln aufgemauert. Im Boden nimmt die Festigkeit der Röhre ab und besteht im gekrümmten Teil des U nur noch aus einer Schleimhülle, an der außen einige Bodenpartikel haften.

Dem Wachstum des Wurmes entsprechend werden die Wohnröhren an dieser instabilen Stelle nach unten hin verlängert. Manchmal wird seitlich ein Gang angeschlossen. Nur selten wird eine neue größere Röhre gebaut.

2. Polydora quadrilobata zwängt sich in das Lückensystem von Sandund Weichböden ein. Dabei wird eine Schleimhülle ausgeschieden, an der das umgebende Sediment anhaftet und in die auch aktiv Baumaterial von der Bodenoberfläche eingefügt wird. Die Schornsteine werden sehr bald, vor $\mathrm{Be}$ endigung des Baus im Boden, hergestellt. Die Schornsteine sind an der Bodenoberfläche oft mit Gespinstfäden an größeren Sandkörnern verankert. 
3. Polydora ligni und redeki siedeln in harten Tonböden. Sie bauen ihre Wohnröhren in taschenförmige Vertiefungen ein, die mit Hilfe der messerartigen Borsten des fünften Segmentes in das Sediment geraspelt werden.

4. Polydora ciliala lebt eingebohrt in Kalkstein und verschiedene Molluskenschalen. Die selbstgeschaffenen Vertiefungen sind mit einer Wohnröhre aus Schleim und Fremdkörpern ausgekleidet.

Die Bohrweise wurde wie folgt untersucht:

a) Im Experiment wird von erwachsenen Würmern an der Gesteinsoberfläche eine aus Sand und Schleim bestehende Wohnröhre gebaut, diese mit Gespinstfäden verankert und kleine Schornsteine aufgesetzt. Aus dieser Röhre heraus bohrt sich der Wurm in den Stein ein und kleidet die Höhlung später mit einer Röhre aus. Die Herstellung eines Bohrloches im Aquarium dauerte fast zwei Monate. Eine direkte Beobachtung des Bohrvorganges war daher nicht möglich.

b) In harte Tonböden bohrt sich $P$. ciliata (juv. und ad.) auf die gleiche Weise wie $P$. ligni und $P$. redeki mit den Borsten des fünften Segmentes ein.

c) Die in Kalkmaterial hergestellten Bohrlöcher und unfertige Bohrungen gleichen denen, die in Ton mechanisch hergestellt werden.

d) Kratzspuren in unfertigen Bohrlöchern und zwischen den feinen Schichten der Molluskenschalen zeigen, daß die Borsten auch bei der Herstellung von Bohrlöchern in Kalk beteiligt sind.

e) In den Molluskenschalen wird die Calcitschicht am stärksten angebohrt. Diese hat eine größere Härte, ist aber von Säure weniger leicht anzulösen als die Arragonitschicht. Die Prismenanordnung in Kalkstein und Molluskenschalen ist, wie Anschliffe zeigten, in den angebohrten Lagen senkrecht, fedrig oder nur leicht geneigt und meist sehr locker.

Auf den Hartböden lebt $P$. ciliata vergesellschaftet mit zahlreichen bohrenden Arten, insbesondere mit perforierenden Algen, welche die prismatische Struktur des Kalkes in ein feines Maschenwerk auflösen.

f) Die als Werkzeug anzunehmenden Borsten des fünften Segmentes zeigen nach der Bohrtätigkeit im Kalkstein meist sehr deutliche Abnützungsspuren. Die Muskulatur, welche die Borsten bewegt, ist besonders kräftig entwickelt.

g) An den mittleren Körpersegmenten liegen Drüsen, die ein saures Sekret produzieren. Dies veranlaßte verschiedene Autoren zu der Annahme einer chemischen Bohrweise. Saures Sekret wird aber auch von vielen anderen nicht bohrenden Polychätenarten sezerniert. In der Spreite zwischen den Röhrenschenkeln liegen in den Bohrlöchern feine Kalksplitter. Diese müßten, wenn der Wurm mit Hilfe von Säure bohrt, aufgelöst oder zu Gips verwandelt werden (PrelL).

Nach diesen Befunden ist für adulte Polydora ciliata eine mechanische Bohrweise anzunehmen.

5. Die Wohnröhre von Pygospio elegans ist gerade und sehr gleichmäßig gemauert. Abzweigungen sind durch Röhrenverletzungen bedingt. (Bestätigung einer Annahme von Linke.) Es wird immer nur ein Röhrenast bewohnt, der andere wird zugemauert.

An Steinen oder an der Innenwand von leeren Molluskenschalen verspinnt der Wurm seine Röhre ähnlich wie Polydora ciliata, bohrt sich jedoch nie in die Hartböden ein.

Struktur und Funktion eines an der Röhrenspitze liegenden Filternetzes werden beschrieben.

6. Die verschiedene Wohnweise von Pygospio elegans und den Polydora- 
Arten steht in Beziehung zu Unterschieden im Bau der Tentakeln, der Borstenbewaffnung und deren Muskulatur.

7. Die Polydoren sind zu den Strudlern und Pygospio zu den Tastern zu rechnen. In diatomeenreichen Sandgebieten tritt Pygospio als Diatomeenfresser auf. So kommt es zur besonders dichten Besiedlung mancher Biotope (Steilküsten, Diatomeensande). Die Verschiedenartigkeit der Ernährungstypen steht in Beziehung zu Unterschieden im Bau des Kopfabschnittes.

8. Einige Beobachtungen über die Brutpflege der Spioniden und das Festsetzen der Larven werden beschrieben. wiesen.

9. Es wird auf die geologische Auswertbarkeit der Ergebnisse hinge-

\section{Literaturverzeichnis}

Andrews, E. A., 8891: A Commensal Annelid. The American Naturalist 25.

Anke1, W. E., 1936: Prosobranchia. Grimpe \&. Wagler, Tierwelt der Nord- und Ostsee 9 b1.

Aurivilliu s, C. W. S., 1891: Über Symbiose als Grund accessorischer Bildungen bei marinen Gastropodengehäusen. Kongl. Svenska Vetenskaps-Akademiens Handlingar 24.

Ax, P., 1951: Die Turbellarien des Eulitorals in der Kieler Bucht. Zool. Jahrb. Abt. System. Okol. u. Geogr. d. Tiere 80.

Bøggild, O. B., 1930: The shell structure of the molluscs. Kgl. Danske Vidensk. Selsk. Skrifter, Naturw. math. Afd. 2.

Carazzí, D., 1895: Revisione del genere Polydora Bosc. e cenni su due specie che vivono sulle ostriche. Mitt. Zool, Stat. Neapel 11.

Caspers, H., 1950: Die Lebensgemeinschaft der Helgoländer Austernbank. Helgol. Wiss. Meeresunters. 3.

Cla paréde, Ed., 1863: Beobachtungen über Anatomie und Entwicklungsgeschichte wirbelloser Tiere an der Küste der Normandie angestellt. Leipzig 1863.

- 1870: Les Annelides Chétopodes du Golfe de Naples, Supplement. Mem. Soc. Phys. Hist. Nat. de Genève 20.

Daqué, E., 1921: Vergleichende biologische Formenkunde der fossilen niederen Tiere. Berlin 1921.

Dales, R. P. 1955: Feeding and digestion in Terebellid Polydhaetes. J. Mar. biol. Ass. U. K. 34.

Elias on, A., 1920: Biologisch-faunistische Untersuchungen aus dem Oresund. Lunds Universitäts Arskrift 16.

Friedrich, H, 1938: Polychacta. Grimpe \& Wagler, Tierwelt der Nord- u: Ostsee 6, a.

Hagmeier, A., u. R. Kändler, 1927: Neue Untersuchungen im nordfriesischen Wattenmeer und auf den fiskalischen Austernbänken. Wiss. Meeresunters. Abt. Helgoland 15.

Hannerz, L., 1956: Larval development of the Polychaete Families Spionidae Sars, Disomidae Mesnil, and Poecilochaetidae n. Fam. in the Gullmar Fjord (Sweden). Zool. Bidrag Uppsala 31.

Harley, M. B., 1950: Occurence of a filter-feeding mechanism in the polychaet Nereis diversicolor. Nature 165.

Hempel, C., 1957: Uber die Okologic einiger Spioniden der deutschen Küsten. Kieler Meeresf. 13 (im Druck)

Hunt, O. D., 1925: The food of the bottom fauna of the Plymouth fishing grounds. J. Mar. Biol. Ass. U. K., N. S. 13.

Jacobi, R., 1883: Anatomisch-histologische Untersuchungen der Polydoren der Kieler Bucht. Inaug. Diss. Kiel, 1883.

Klöhn, H., 1936: Die Anlösungsgeschwindigkeit kalkiger anorganischer und organischer Körper innerhalb eines wäßrigen Mediums. Zbl. Mineral Geol. Pal. 1936.

Lankester, E. R., 1868: On Lithodomous Annelids. Ann. Mag. Natur. Hist. Ser. 4, 1.

Linke, O., 1939: Die Biota des Jadebusenwattes. Helgol. Wiss. Meeresunters. 1.

McIntosh, W. C., 1915: A Monograph of the British Marine Annelids 3.

Marcus, E., 1926: Bryozoa. Grimpe \& Wagler, Tierwelt der Nord- und Ostsee $7 \mathrm{c}$.

Mecznikow, E., 1865:: Beiträge zur Kenntnis der Chactopoden. Ztschr. Wiss. Zool. 10. 
Prel1, H., 1925: Fossile Wurmröhren. Beitr. zur palaeobiol. Beurteilung der PolydorinenHorizonte. Neues Jahrb. Mineral. Geologie u. Palaeontologie, Beilage 53, Abt. B.

Ra uschenplat, E., 1901: Über die Nahrung von Tieren aus der Kieler Bucht. Wiss. Meeresunters. Abt. Kiel, N. F. 5.

Remane, A., 1933: Verteilung und Organisation der benthonischen Mikrofauna in der Kieler Bucht. Wiss. Meeresunters. Abt. Kiel 21.

- 1940: Einführung in die zoologische Okologie der Nord- und Ostsee. Grimpe \& Wagler, Tierwelt der Nord- und Ostsee 1 a

Richter, R., 1924: Flachseebeobachtungen zur Palaeontologie und Geologie. Senckenbergiana 6 .

- 1927: Die fossilen Fährten und Bauten der Würmer. Ein Öberblick über ihre biolagischen Grundformen und deren geologische Bedeutung. Palaeontol. Zeitschr. 9.

Söderström, A., 1920: Studien über die Polychaeten-Familic Spionidae. Uppsala 1920.

- 1923: Uber das Bohren der Polydora ciliata. Zool. Bidrag Uppsala 1923.

Steen, J., 1882: Anat. hist. Unters. v. Terebellides Strömii M. Sars. Zeitschr. f. Naturw. 16.

Swa mmerdam, J., 1737: Biblia natura. (Leyden 1737).

Tauber, A. F., 1944: Über prämortalen Befall von rezenten und fossilen Molluskenschalen durch tubicole Polychaeten (Spioniden). Palaeobiol. 8.

Thamdrup, H. M., 1935: Beiträge zur Ókologie der Wattenfauna auf experimenteller Grundlage. Medd. Komm. Danmarks Fiskeri- og Havunders. Ser. Fiskeri, 10.

Thors on, G., 1946: Reproduction and larval development of Danish marine bottom invertebrates. Medd. Komm. Danmarks Fiskeri- og Havunders., Ser. Plankton 4.

Watson, A. T., 1891: The protectiv device of an annelid. Nature (London) 44.

- 1907: Habits of Tube-building worms. Rep. Brit. An. Adv. Sci.

Werner, B., 1951: Über die Bedeutung der Wasserstromerzeugung und Wasserstromflitration für die Nahrungsaufnahme der ortsgebundenen Meeresschnecke Crepidula fornicata L. Zool. Anz. 146.

Wetzel, W., 1937: Die Schalenzerstörung durch Mikroorganismen. Erscheinungsform, Verbreitung und geol. Bedeutung in Gegenwart und Vergangenheit. Kieler Meeresf. 2.

Whitelegge, T., 1890: Report on the worm disease affecting the oysters on the coast of New South Wales. Rec. Austral. Mus. 1.

Wils on, D. P., 1928: The Larvae of Polydora ciliata Johnston and Polydora huplura Clap. J. Mar. Biol. Ass. U. K. 15.

Zi egelmeier, E., 1952: Beobachtungen über den Röhrenbau von Lanice conchilega Pallas im Experiment und am natürlichen Standort. Helgol. Wiss. Meeresunters. 4.

- 1954: Beobachtungen über den Nahrungserwerb bei der Naticide Lınatia nitida Denovan (Gastropoda Prosobranchia). Helgol. Wiss. Meeresunters. 5. 